\title{
Heat-Shock Proteins in Neuroinflammation
}

OPEN ACCESS

Edited by:

Chrisostomos Prodromou, University of Sussex,

United Kingdom

Reviewed by:

Gregory L. Blatch,

University of Notre Dame Australia, Australia Brian Blagg,

University of Notre Dame,

United States

Laura J. Blair,

University of South Florida,

United States

*Correspondence:

Melinda E. Tóth

toth.erzsebetmelinda@brc.mta.hu

tThese authors have contributed equally to this work.

Specialty section:

This article was submitted to

Neuropharmacology,

a section of the journal

Frontiers in Pharmacology

Received: 25 April 2019

Accepted: 22 July 2019

Published: 27 August 2019

Citation:

Dukay B, Csoboz B and Tóth ME (2019) Heat-Shock Proteins in Neuroinflammation.

Front. Pharmacol. 10:920. doi: 10.3389/fphar.2019.00920

\begin{abstract}
Brigitta Dukay ${ }^{1,2 \dagger}$, Bálint Csoboz ${ }^{1 \dagger}$ and Melinda E. Tóth ${ }^{1 *}$
${ }^{1}$ Institute of Biochemistry, Biological Research Centre, Hungarian Academy of Sciences, Szeged, Hungary, ${ }^{2}$ Doctoral School in Biology, Faculty of Science and Informatics, University of Szeged, Szeged, Hungary
\end{abstract}

The heat-shock response, one of the main pro-survival mechanisms of a living organism, has evolved as the biochemical response of cells to cope with heat stress. The most well-characterized aspect of the heat-shock response is the accumulation of a conserved set of proteins termed heat-shock proteins (HSPs). HSPs are key players in protein homeostasis acting as chaperones by aiding the folding and assembly of nascent proteins and protecting against protein aggregation. HSPs have been associated with neurological diseases in the context of their chaperone activity, as they were found to suppress the aggregation of misfolded toxic proteins. In recent times, HSPs have proven to have functions apart from the classical molecular chaperoning in that they play a role in a wider scale of neurological disorders by modulating neuronal survival, inflammation, and disease-specific signaling processes. HSPs are gaining importance based on their ability to fine-tune inflammation and act as immune modulators in various bodily fluids. However, their effect on neuroinflammation processes is not yet fully understood. In this review, we summarize the role of neuroinflammation in acute and chronic pathological conditions affecting the brain. Moreover, we seek to explore the existing literature on HSP-mediated inflammatory function within the central nervous system and compare the function of these proteins when they are localized intracellularly compared to being present in the extracellular milieu.

Keywords: neuroinflammation, heat shock proteins, heat shock response, diseases of the central nervous system, extracellular heat shock proteins, inflammation modulation

\section{INTRODUCTION}

Neuroinflammation is a well-known feature of different acute brain disorders including ischemic stroke, traumatic brain injury, and chronic neurodegenerative diseases such as Alzheimer's (AD) and Parkinson's (PD) diseases (Kim and Yenari, 2013; Banjara and Ghosh, 2017). It is characterized by an increased level of cytokines and chemokines with concomitant activation of glial cells and the infiltration of leukocytes (Kim and Yenari, 2013).

Activation of the inflammatory cascades within these cells is mediated by specialized patternrecognition receptors (PRRs) like toll-like receptors (TLRs) and NOD-like receptors (Banjara and Ghosh, 2017). PRRs recognize different danger signals triggering immune response. These danger signals can be external, mainly pathogen-derived molecules (pathogen-associated molecular patterns-PAMPs). On the other hand, tissue injury after ischemic stroke or during chronic neurodegenerative diseases can lead to sterile inflammation. In these conditions, the release of endogenous damage-associated molecules (danger-associated molecular pattern-DAMP) activates 
the inflammatory cascade (Banjara and Ghosh, 2017). DAMPs could flow out from necrotic cells or they can be secreted specifically by damaged cells to trigger the immune response to clean cell debris and initiate tissue repair (Giuliano et al., 2011).

DAMPs are very diverse regarding their origin and chemical properties. They include uric acid, extracellular ATP, mitochondrial DNA, misfolded proteins like $\beta$-amyloid $(A \beta)$, glycoproteins, hormones, and extracellular RNA (Patel, 2018). Moreover, heat-shock proteins (HSPs) appear to be ideal DAMPs, as they are highly conserved molecules, one of the most abundant intracellular proteins whose expression is further increased upon tissue injury like thermal or oxidative stress or in response to infections. As molecular chaperones, HSPs are able to bind several peptides suggesting that they can be involved in antigen presentation. Moreover, HSPs themselves are able to trigger the inflammatory response (Giuliano et al., 2011).

DAMPs can bind to the PRRs of microglia and other immune cells leading to the stimulation of inflammatory cascades by the activation of different pro-inflammatory transcription factors like nuclear factor kappa B (NF-kB) (Kim and Yenari, 2013; Banjara and Ghosh, 2017). Under normal conditions, the inactive heterodimeric NF- $\kappa \mathrm{B}$ is bound by its inhibitor NF- $\kappa \mathrm{B}$ inhibitor beta $(\mathrm{IkB})$ in the cytosol. Activation of the inflammatory cascade results in the phosphorylation and degradation of $\mathrm{IkB}$, releasing NF- $\kappa B$. The activated transcription factor then moves to the nucleus, initiating the expression of several inflammatory factors like cytokines and chemokines (Kim and Yenari, 2013).

The condition of the brain tissue is constantly monitored by glial cells, primarily microglia and astrocytes (Banjara and Ghosh, 2017). Brain-resident microglia cells are the first responders to central nervous system (CNS) damage; they accumulate within a short period of time in the injured area and begin the phagocytic removal of myelin debris, which is important because this debris can release axonal regrowth-inhibiting factors. Moreover, activated microglia also play an important role in glial scar formation and in support of the blood-brain barrier (BBB) (Mosley and Cuzner, 1996; Schwab, 2004; Davalos et al., 2005; Lou et al., 2016; Xu et al., 2019). However, through their TLRs, DAMPs activate the pro-inflammatory phenotype of microglia besides the early phagocytic phenotype, which is destructive to the brain tissue since it can produce pro-inflammatory cytokines, chemokines, complement system components, free radicals, and matrix metalloproteases (MMPs) which could result in an increase in BBB permeability and apoptosis (Walker et al., 1995; Jack et al., 2005; Yenari et al., 2006; del Zoppo et al., 2012; Kawabori and Yenari, 2015). Activation of microglia is the first step in the inflammatory response of the brain, followed by the activation and proliferation of astrocytes, contributing to an even more robust secretion of pro-inflammatory signaling molecules (Banjara and Ghosh, 2017). The released chemokines play a major role in the activation of peripheral immune cells (Glabinski et al., 1995). In response to inflammatory factors, neutrophils rapidly infiltrate into the affected brain areas. Like glia, they produce inflammatory mediators and reactive oxygen species and can be the source of high MMP levels in the injured area, thereby enhancing neurotoxicity, contributing to vascular permeability, and causing cerebral edema. On the other hand, by phagocytosis and production of growth factors, neutrophils can also take part in restoration of the damaged area (Schoettle et al., 1990; Soares et al., 1995; Nguyen et al., 2007; Rosell et al., 2008; Liu et al., 2018a). Peripheral monocytes are also able to enter the brain parenchyma a few hours after injury. When the peripheral monocyte encounters traumatized or infected tissue, it is differentiated into a macrophage or a dendritic cell. The infiltrating macrophages are primarily cytotoxic, but their function can vary depending on whether the pro- or the antiinflammatory phenotype is dominant; therefore, they can have a role in phagocytosis, cytokine/chemokine release, antigen presentation, astroglial scar formation, and tissue repair (Girard et al., 2013; Vogel et al., 2014; Gliem et al., 2016; Frik et al., 2018; Malo et al., 2018). Dendritic cells are important in both innate and adaptive immune responses, but their predominant role is antigen presenting by which antigen-specific $\mathrm{T}$ cells are being activated and migrated into the brain (Felger et al., 2010; Malo et al., 2018). Thus, the switch from non-specific innate immune response to the adaptive response is triggered by the appearance of T cells, which are activated via antigens presented by dendritic cells, macrophages, and microglia. Different types of T lymphocytes have different roles. CD4 + ("helper") T cells control the adaptive immune response, while CD8 + ("killer") $\mathrm{T}$ cells kill infected and damaged cells. T-cell infiltration after injury is mostly neurotoxic: it releases interferon gamma (INF $\gamma$ ) and other inflammatory cytokines, but it can also have a protective role. T regulatory cells can protect against inflammation in many ways, including expression of tumor growth factor beta (TGF- $\beta$ ) and interleukin-10 (IL-10) (Ford et al., 1996; Liesz et al., 2009; Gill and Veltkamp, 2016; Malo et al., 2018).

\section{Role of Neuroinflammation in Different Acute and Chronic CNS Diseases}

Inflammation has a key role in most acute and neurodegenerative CNS disorders. However, it is complicated to define if inflammation is a cause or consequence of neuronal cell death in different CNS diseases. Neuroinflammation can naturally occur in response to many acute damaging effects, such as pathogenic invasion or tissue injury being the first line of defense of the brain tissue (Swaroop et al., 2016; Banjara and Ghosh, 2017). Activated immune cells combat against pathogens and eliminate damaged tissue, thereby, preventing the spread of infection and necrosis. However, we should not neglect the Janus-faced nature of inflammation. In addition to protective functions, an excessive, over-activated inflammatory response may lead to further neuronal damage (reviewed recently in Le et al., 2016; Banjara and Ghosh, 2017; Sochocka et al., 2017). In the case of chronic, age-related neurodegenerative diseases, inflammation seems to have a central role in the pathology of the disease. Since the development of these disorders is a slow process, the underlying pathophysiological mechanisms induce a constant immune response in the brain, leading to chronic inflammation. While a rapid, acute course of inflammation which induces an immune reaction within a relatively short period of time can have beneficial effects, prolonged inflammation triggered by continuously present insults usually leads to the destruction of 
brain tissue. Additionally, persistent activation interferes with the normal, beneficial housekeeping functions of resident cells of the brain, such as microglia and astrocytes. Although these cells can be involved in the elimination of pathological protein aggregates, they go through cellular senescence with age and are less able to perform their physiological functions (Floden and Combs, 2011; Caldeira et al., 2017; Gomez-Arboledas et al., 2018). Along with aging, the integrity of the vascular network also decreases (Elahy et al., 2015; Montagne et al., 2015), allowing systemic immune processes to affect the brain, which is in turn no longer immuneprivileged. These processes could lead to the dysregulation of immune mechanisms in the CNS and to the development of a pro-inflammatory milieu, which could advance the progression of neurological diseases and neurodegeneration (reviewed in Costantini et al., 2018).

The tissue injury caused by acute, sterile brain-damaging conditions like ischemic stroke and by traumatic brain injury could be very similar to each other. After cerebral artery occlusion, a core region is formed where the blood flow ceases and the subsequent glucose and oxygen deficiency completely eliminate the neurons and glial cells. This is surrounded by a so-called penumbra, where there is still a limited blood perfusion which already damages the cells but does not lead to cell death (Zhang et al., 1997; Lee et al., 2000). Similarly, in the traumatized brain area, hypoperfusion and local ischemia also develop. In both cases, the impacts are followed by reperfusion, which is indispensable in the restoration of brain oxygen and nutrient supply, yet causes inflammatory processes and secondary tissue damage (Coles, 2004; Lin et al., 2016). After injury, the amount of the two major pro-inflammatory cytokines, IL-1 $\beta$ and tumor necrosis factor (TNF)- $\alpha$, increases in the core and penumbra regions after a few hours by expression of resident CNS cells. This activates additional microglia and astrocyte cells, increases the production of chemokines, the level of apoptosis, the permeability of the $\mathrm{BBB}$, and edema formation (Feuerstein et al., 1994; Sairanen et al., 2001; Rothwell, 2003; Hosomi et al., 2005; Lu et al., 2005; Sozen et al., 2009). Under experimental conditions of stroke and traumatic brain injury, the suppression of proinflammatory cytokines could prevent the loss of interneurons and oligodendrocytes, reduce the infarct area, thereby alleviating cognitive impairment, and also affect the efficacy of repair mechanisms in the long term (Scherbel et al., 1999; Flygt et al., 2018; Newell et al., 2018; Wang et al., 2018a; Wong et al., 2019). In addition to the therapeutic inhibition of pro-inflammatory cytokines, the targeting of anti-inflammatory cytokines could also be potentially relevant in the therapy of neurological diseases. In animal experiments, IL-10 administration decreased the size of the infarct area after middle cerebral artery occlusion and downregulated pro-inflammatory signaling, while following traumatic brain injury, it also reduced TNF- $\alpha$ and IL-1 levels and increased neural repair processes (Knoblach and Faden, 1998; Spera et al., 1998; Liesz et al., 2014).

Recently, a potential neuroprotective role for microglial cells was described when the inhibition of microglia has led to increased astrocyte activation and increased infarct size by $60 \%$ after focal brain injury (Szalay et al., 2016; Jin et al., 2017). The role of microglia in brain injury could be dual, as they are able to form a barrier between the injured and healthy tissue with their projections and support the glia limitans (Davalos et al., 2005; Roth et al., 2014), while activated microglial cells have been shown to be neurotoxic and to induce apoptosis and exacerbate inflammatory processes in other studies (Kaushal and Schlichter, 2008; Hu et al., 2012; Figure 1A).

Acute trauma reduces the integrity of the cerebral microvascular network (Chodobski et al., 2011). In addition, the released chemokines facilitate the entry of neutrophils, monocytes, and T cells (Dimitrijevic et al., 2007; Llovera et al., 2017). Experimental data from numerous studies have confirmed that the influx of neutrophils and monocytes is predominantly pro-inflammatory and harmful. For example, after intracerebral hemorrhage formation, neutrophils were shown to contribute to MMP-9-mediated BBB damage, to white matter destruction, and to the increased damaging effect of glial cells to the brain (Moxon-Emre and Schlichter, 2011). However, it is important that peripheral macrophages with high phagocytic capacity also appear $72 \mathrm{~h}$ after middle cerebral artery occlusion (Ritzel et al., 2015). Their beneficial role is demonstrated by the fact that, after ischemia, the use of the chemokine receptor type 2 (CCR2) antibody reduced the level of anti-inflammatory cytokines and long-term repair processes (Wattananit et al., 2016). The appearance of $\mathrm{T}$ cells in the acute phase exacerbates brain damage; accordingly, $\mathrm{T}$ cells are crucial to the development of secondary neurodegeneration. This is supported by experiments, in which the inhibition of IL-17 produced by $\gamma \delta$ T-cells, or IL-2 1 expressed by CD4+ T-cells successfully reduced the infarct size and protected against middle cerebral artery occlusion (Clarkson et al., 2014; Arunachalam et al., 2017). On the other hand, regulatory $\mathrm{T}$ cells activated in later phase were proved to be protective. In an animal model of stroke, regulatory $\mathrm{T}$ cells reduced the level of astrocyte activation and increased the production of anti-inflammatory cytokines (Ito et al., 2019).

In many age-related neurodegenerative disorders, aggregationprone proteins accumulate in neurons, such as $\mathrm{A} \beta$ and tau in $\mathrm{AD}$, a-synuclein in PD or huntingtin in Huntington's disease (HD). These proteins tend to form insoluble inclusion bodies within the brain tissue, which can initiate a chronic inflammatory response (Khandelwal et al., 2011; Yang et al., 2017). The importance of the role of inflammation and microglia function in the pathogenesis of neurodegenerative diseases is supported by large-scale genetic studies (Malik et al., 2015; Gelders et al., 2018). Several single nucleotide polymorphisms have been identified associated with $\mathrm{AD}$ in genes related to microglial phagocytosis or the complement system, such as ABCA7, CD33, and CR1 (Lambert et al., 2009; Hollingworth et al., 2011; Naj et al., 2011). A missense mutation in the gene expressing triggering receptor expressed on myeloid cells 2 (TREM2) was found to be a significant risk factor not only for AD (Jonsson et al., 2013) but for frontotemporal dementia and PD as well (Rayaprolu et al., 2013). TREM2 is involved in the activation of microglial phagocytosis without the increase of cytokine production; therefore, it can possibly stimulate the elimination of $\mathrm{A} \beta$ plaques and apoptotic neurons (Rayaprolu et al., 2013; Savage et al., 2015). In the brain of AD patients, microglia were proved to migrate toward the amyloid plaques and to become more stimulated by binding to $A \beta$. This sustained 


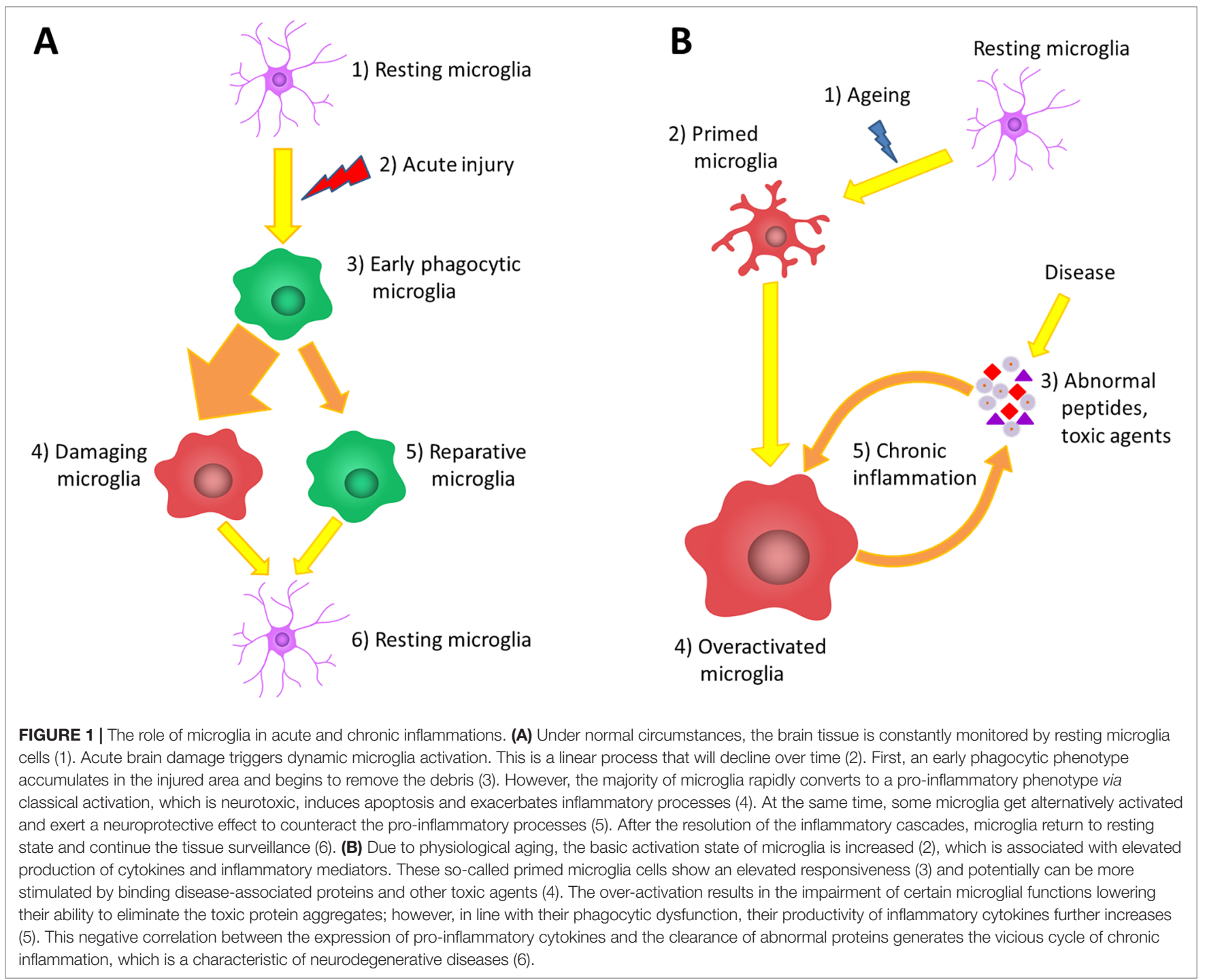

microglia activation results in the impairment of microglial functions, like motility and phagocytosis, lowering their ability to eliminate these toxic protein aggregates from the brain ( $\mathrm{Su}$ et al., 2008; Stewart et al., 2010; Krabbe et al., 2013). In line with the loss of their phagocytic capacity by decreased scavenger receptors and amyloid-degrading enzymes, the productivity of inflammatory cytokines further increased in an aged APP/PS1 animal model of AD. This negative correlation between the expressions of IL- $1 \beta$, TNF- $\alpha$, and A $\beta$ clearance generates neuronal damage (Hickman et al., 2008; Figure 1B). Earlier results showed that IL- $1 \beta$ expression can further stimulate the synthesis and cleavage of amyloid precursor protein, leading to $A \beta$ deposition, which activates the vicious cycle of $A \beta$-induced inflammation (Goldgaber et al., 1989; Buxbaum et al., 1992). Although in the $3 x$ Tg-AD model, microglial activation by IL- $1 \beta$ was shown to be useful in removing amyloid plaques; at the same time, it also increased the neurotoxicity of the tau protein (Ghosh et al., 2013). Extracellularly secreted hyperphosphorylated tau can also trigger the activation of microglia and astrocytes with a concomitant increase of cytokine release (reviewed in Laurent et al., 2018). In turn, the increased inflammation and glia activation were shown to provoke tau hyperphosphorylation exacerbating tau neuropathology in 3xTg-AD mice (Kitazawa et al., 2005). Activated microglial cells with decreased ramification have been detected in the brain of HD patients and in the YAC128 mouse model of the disease as well (Politis et al., 2011; Franciosi et al., 2012). In vitro and transgenic mouse studies showed that healthy microglia can help to remove dysfunctional neuronal cells and restrain the progression of the disease (Kraft et al., 2012; Benraiss et al., 2016). In contrast, transplantation of mutant huntingtinexpressing human glial cells into normal mice worsened their motoric performance (Benraiss et al., 2016). These results suggest that, similarly to $\mathrm{AD}$ and $\mathrm{PD}$, abnormal microglial function has a crucial role in the pathogenesis of HD.

In addition, the inflammasomes of infiltrating monocytes and in microglia can be activated by $A \beta$, which further enhances the production of IL-1 $\beta$ and IL-18 (Halle et al., 2008; Saresella et al., 2016). TNF- $\alpha$ was also shown to be elevated in the cerebrospinal 
fluid of $\mathrm{AD}$ patients and was described to be a risk factor in $\mathrm{PD}$ (Tarkowski et al., 2003; Lindenau et al., 2017). In the APP23 transgenic mouse model of $A D$, suppression of the TNF- $\alpha$ receptor 1 diminished $A \beta$ production and plaque formation by reducing BACE1 activity, which, in parallel, reduced diseaseassociated cognitive dysfunctions (He et al., 2007). The role of the anti-inflammatory IL-10 is controversial, as its elevated expression lowers the level of pro-inflammatory cytokines and chemokines, which is important for restoring immune balance, yet in excess, it restrains the activated microglia around plaques causing reduced A $\beta$ phagocytosis (Szczepanik et al., 2001; Guillot-Sestier et al., 2015).

Beside microglia, astrocytes can also contribute to the neurotoxicity triggered by disease-associated proteins. In the brain of $\mathrm{AD}$ and $\mathrm{PD}$ patients, reactive astrogliosis appears, and its distribution is associated with the presence of $\alpha$-synuclein containing Lewis bodies and A $\beta$ senile plaques (Braak et al., 2007; Medeiros and LaFerla, 2013). Since astrocytes take part in the formation of the $\mathrm{BBB}$, their activation in old mice compared to young ones promoted barrier dysfunction, which occurs during normal ageing, increasing the risk of disease development (Elahy et al., 2015). Primary astrocytes isolated from AD mice showed a highly induced BACE-1 expression and amyloid precursor protein secretion upon IFN $\gamma$ treatment, presuming the role of astrocytes in amyloidosis (Hong et al., 2003). In contrast, a study in which wild-type astrocytes were transplanted into the brain of a mouse with $\mathrm{AD}$ demonstrates the capacity of astrocytes to degrade A $\beta$ (Pihlaja et al., 2011). In PDGF $\alpha$-synuclein transgenic mice, astrocytes took up neuronal cell-derived $\alpha$-synuclein which stimulated the release of pro-inflammatory cytokines, chemokines, and other inflammatory mediators (Lee et al., 2010).

Peripheral immune cells, like macrophages, were shown to assemble around $\mathrm{A} \beta$ deposits to eliminate them in the mouse model of AD. Furthermore, in different models of AD, an increased load of amyloid occurred after the restriction of mononuclear phagocyte infiltration into the brain or with the removal of $\mathrm{CD} 11 \mathrm{~b}+$ macrophages from the parenchyma (Simard et al., 2006; El Khoury et al., 2007). In contrast, macrophages from $\mathrm{AD}$ patients presented a limited internalization of $A \beta$, suggesting a phagocytic dysfunction compared to the control macrophages (Fiala et al., 2005). It has been reported that the lack of CD36, which is needed for amyloid binding and which cooperates with TLR4 and TLR6 receptors, attenuated A $\beta$ accumulation and NLRP3 activation in macrophages (Sheedy et al., 2013). The adaptive immune system is also involved in the pathogenesis of neurodegeneration, which is demonstrated by the elevated level of $\mathrm{A} \beta$-reactive T-cells in $\mathrm{AD}$ patients and even in healthy elderly humans and by the $\alpha$-synuclein specific T-cell response in PD (Monsonego et al., 2003; Sulzer et al., 2017). In PD patients, well-characterized parts of the $a$-synuclein were recognized as epitopes which mostly stimulated the IL-5-expressing CD4+ cells and the cytotoxic IFN $\gamma$-producing CD8+ cells; moreover, the activation of CD4+ T-cells was accompanied by the injury of dopaminergic neurons (Brochard et al., 2009; Sulzer et al., 2017).

These results show that, after acute injuries, the immune cells are rapidly activated in order to eliminate cellular debris; however, the immune response should be mitigated in the right time, as the excessive cytokine release could promote further neuronal damage. In chronic neurodegenerative diseases, the toxic protein aggregates are generated persistently inducing a chronic immune response. Microglial and macrophage cells are assumed to clear the protein inclusions; however, during aging and in neurodegenerative diseases, their phagocytic activity declines due to cellular senescence (Luo et al., 2010; Costantini et al., 2018), while there is an increase in cytokine production. Taken together, it seems that both the lack and exaggeration of inflammatory responses can promote neuronal damage; therefore, it should be tightly regulated. In the next sections, we attempt to summarize the immunomodulatory roles of HSPs. Many evidences suggest that HSPs have several moonlighting functions through which they can be involved in the regulation of immune cell activity and cytokine release. Therefore, the modulation of HSP levels could serve as potential therapeutic applications to treat CNS diseases related to inflammation.

\section{Intracellular HSPs and the Heat-Shock Response}

Living organisms can be subjected to environmentally constrained challenges. To survive, they have to counter these unfavorable conditions by adaptation. The term cellular stress response summarizes universal cellular reactions to a wide variety of environmental challenges (Kültz, 2005). Among the many cellular survival mechanisms, the response to heat stress is amongst the most ancient and conserved (Horváth et al., 2008). Heat stress induces multi-leveled signaling in cellular systems termed as the heat-shock response. The heat-shock response was originally defined as the biochemical response of cells to heat stress (Lindquist, 1986). Although it has been primarily described to be induced by increased temperatures, it has also been recognized that the heat-shock response can be activated by a wider range of cellular stressors like membrane perturbations, heavy metals, oxidative stress, or by pathophysiological conditions (Morimoto, 1998; Vigh et al., 2007; Balogh et al., 2013). One of the most characterized aspects of the heat-shock response is the accumulation of a conserved set of HSPs. HSPs primarily act as chaperones within the cell by aiding the folding of proteins, the refolding of denatured proteins, and by guiding the degradation of irreversibly damaged proteins. Therefore, HSPs are involved in the maintenance of protein homeostasis by alleviating the unfavorable changes caused by heat stress (Kampinga, 2006). HSPs consist of many different families differentiated by their molecular weight. In 2009, Kampinga and co-workers proposed a new nomenclature of human HSP families (Kampinga et al., 2009). Small HSPs (sHSPs) are the most diverse set of HSPs, consisting of proteins within a $12-43 \mathrm{kDa}$ range. They can form multimeric complexes and display a wide range of cellular functions. The sHSPs coaggregate with aggregationprone proteins to initiate efficient disaggregation. The release of substrate proteins from the transient sHSP reservoirs and their refolding require cooperation with ATP-dependent chaperone systems (Van Montfort et al., 2001). The sHSP holdase, HSPB1, can form large oligomeric structures which can act as molecular chaperones sequestering unfolded proteins and inhibiting 
subsequent aggregation and insolubilization (Singh et al., 2017). HSPB1 is additionally involved in actin polymerization/ depolymerization (Tang, 2015). HSPD1 is an ATP-dependent unfoldase. The HSPD1 proteins in eukaryotes are localized to the mitochondria and are responsible for mitochondrial protein import and macromolecular assembly within this compartment (Koll et al., 1992). HSPA1 is most likely the best-characterized chaperone. The HSPA proteins act together with their many co-chaperones, working as a "HSPA chaperone machinery" (Kampinga and Craig, 2010). The most important co-chaperones are the DNAJ family and the nucleotide exchange factors. DNAJ proteins exhibit great diversity; however, all of them include a conserved J domain required for its binding to HSPA1 (Hennessy et al., 2005). DNAJ takes part in the substrate specificity of HSPA1 and can increase the ATPase activity of the HSPA1 protein thereby enhancing their activity. The nucleotide exchange factors promote the dissociation of the ADP from HSPA1. This ATPase cycle regulates the binding and release of the substrate, since HSPA proteins have a higher affinity for unfolded proteins when bound to ADP, and a lower affinity when bound to ATP (Mayer and Bukau, 2005). The HSPA1/DNAJ system participates in the active ATP-dependent folding-refolding of a high number of cellular proteins. On the other hand, the non-refoldable substrates can be selected to proteasomal degradation, which process is mediated by ubiquitin ligases as the CHIP E3 ligase (VanPelt and Page, 2017). HSPC1 is also an ATP-dependent chaperone which facilitates the maturation and/or activation of many "client proteins" involved in signal transduction and transcriptional regulation and is necessary for viability in eukaryotes. HSPC1 is central to processes broadly ranging from cell cycle regulation to protein degradation, and it has also been connected with cellular transformation (Brown et al., 2007). Therefore, the potential utilization of specific inhibitors of HSPC1 for cancer treatment has long been investigated (Schopf et al., 2017; Zuehlke et al., 2018). The proteins in the HSPH family form large hexameric structures with an unfoldase activity in the presence of ATP. These proteins are considered to function as chaperones by recessively threading client proteins through a small pore, thereby providing each client protein with a second chance to fold (Schirmer et al., 1996).

The expression of HSPs occurs under strong transcriptional control. Among eukaryotes, the transcriptional activation of HSP genes is regulated by the family of transcriptional factors termed as heat-shock factors (HSFs). The family consists of four different HSFs, from which HSF1 is the main transcriptional regulator of the HSP genes (Richter et al., 2010). HSF1 is constitutively present in its inactive form in most tissues and cell types in the cytosol. Under stress conditions, HSF1 undergoes a multistep activation process as the cytosolic HSF1 dissociates from HSPA/ HSPC which prevents the interaction of HSF1 monomers. HSF1 trimerizes and subsequently translocates to the nucleus and binds to extended repeats of the sequence nGAAn, termed as heat-shock elements, in the promoter regions of its target genes (Morimoto, 1998). Moreover, in addition to activating the heatshock response, HSF1 is involved in the regulation of many other cellular processes. HSF1 is able to modulate not only the HSP expression but the transcription of other genes as well-for example, it is involved in the regulation of apoptotic cell death, autophagy, the immune response, aging, or even synaptic function (Hooper et al., 2016; Barna et al., 2018). Several studies demonstrated that HSF1 is necessary for the normal function of the immune system, and it can regulate the expression of different inflammatory cytokines and chemokines, although its exact effect has not been fully elucidated yet (Barna et al., 2018).

HSF1 was first suggested to play a role in inflammatory processes when an abundant increase in the pro-inflammatory cytokine TNF- $\alpha$ was observed upon treatment with bacterial lipopolysaccharides (LPS) in HSF1 knockout mice (Xiao et al., 1999). This observation later led to the discovery of the inhibitory regulation of HSF1 over TNF- $\alpha$ by its binding to elements in the promoter (Singh et al., 2002), suggesting an intertwined close regulation between TNF- $\alpha$ signaling and HSF1. In contrast, a recent study showed that heat-shock treatment can induce the expression of TNF- $\alpha$ independently from NF- $\kappa \mathrm{B}$ signaling. The transcription of TNF- $\alpha$ was activated by a multiprotein complex containing HSF1 (Ali et al., 2019), suggesting that the effect of HSF1 on TNF- $\alpha$ expression is likely to be influenced by other factors as well. Another level of interplay has been revealed between heat shock and TNF-mediated inflammatory signaling when TNF- $\alpha$ was described to cause downregulation of HSF1 activation, which was shown to increase apoptotic cell death (Schett et al., 2003). Furthermore, it has been demonstrated that heat pretreatment decreases LPS-induced IL-6 expression in macrophages and mouse embryonic fibroblast cells. The heat-induced HSF1 upregulated the ATF3 transcription factor, a negative regulator of IL-6 expression (Takii et al., 2010). This was a surprising result, as it was previously observed that HSF1 is necessary for the maximal induction of IL-6 in response to LPS treatment without heat shock (Inouye et al., 2007). Under non-stressful conditions, the HSF1 was found to bind directly to IL-6 promoter and, by promoting the opening of the chromatin structure, it may help the access of activator or repressor regulatory molecules (Inouye et al., 2007). However, the IL-6 expression of many tissues and the serum level of IL- 6 were higher in HSF null-mutant mice compared to wild types after LPS injection, suggesting an inhibitory role of HSF1 on IL-6 production in vivo (Takii et al., 2010). Heat-shock elements can be found in the promoter region of CXC chemokine genes as well, although a heat shock has gene-specific enhancing or repressing effect on the expression of these genes (Maity et al., 2011). Generally, the increased temperature can exert diverse, both pro- and antiinflammatory effects on macrophage function, a phenomenon that was reviewed in detail by Lee and Repasky. The authors proposed that the cytokine response induced by a mild heat treatment is largely influenced by the specific activation stage of the macrophage cells (Lee and Repasky, 2012).

It is well known that age-related processes or disease conditions can alter the cellular protein homeostasis. The accumulation of misfolded proteins increases constantly in the brain during aging, and probably, this leads to the elevation of the basal HSP level found in different brain regions (Sőti and Csermely, 2000). For example, higher level of HSPB1 and HSPA1 were detected in the olfactory bulb of middle-aged and old rats compared to young ones (Crum et al., 2015). The basal expression of 
HSPA1 was significantly higher in the cortex of old mice as well (Carnemolla et al., 2014). Interestingly, this study also describes a downregulation of HSPB1 in the striatum of old mice (Carnemolla et al., 2014) while others found an age-related increase in HSPB1 level in the striatum, subtantia nigra, and cortex of rats (Gupte et al., 2010; Gleixner et al., 2014). On the other hand, the heatshock response and the inducibility of HSPs decline during aging and in disease conditions (Söti and Csermely, 2000; Calderwood et al., 2009). Such decrease in the activation of HSF1 and thus in the stress inducibility of HSPs might appear in several conditions as it was observed during a DNA damage-initiated senescent program (Kim et al., 2012). The mouse model of HD has also been described to have a reduced heat-shock response (Neueder et al., 2017). An age-associated decrease in HSF1 activation has been observed in several studies: HSF1 activation reduced with age in rat hepatocytes (Heydari et al., 2000) and Caenorhabditis elegans neuronal cells also showed a significant age-associated decrease in HSF1 activation (Kern et al., 2010). Alterations in nutritional lipid supplies were also associated with a reduced heat-shock response in parallel with a marked decrease in the proportions of n-3 and n-6 polyunsaturated fatty acids (Péter et al., 2012). Also, a high-cholesterol diet-induced hyperlipidemia was described to attenuate the expression of HSPA1 following either heat or ischemic treatment in rat hearts (Csont et al., 2002). Based on these results, it is tempting to hypothesize that the impairment in HSF1 activation may not only cause a disturbed protein homeostasis but also an uncontrolled inflammatory process. Unregulated inflammation in the CNS during aging might contribute to the pathogenesis of neuronal diseases. Therefore, restoration of the heat-shock response and the HSF1 activity may help to delay age-related changes in the brain.

\section{HSPs and Their Role in CNS Diseases}

The expression of HSPs could rapidly increase in response to different acute brain injuries, such as ischemic stroke (Sharp et al., 2013). For example, HSPA1 expression is increased in microglia, astrocytes, and endothelial cells in the infarct area, while it is elevated mainly in neurons in the penumbra (Sharp et al., 2000). In contrast, protein levels of HSPB1 are increased almost exclusively in astrocytes and to a lesser extent in certain neurons in the ischemic brain tissue following middle cerebral artery occlusion, and it is thought to stabilize the astrocyte cytoskeleton by binding to GFAP under stress conditions (Sharp et al., 2013). However, another study found that HSPB1 and HSPB5 showed a high level of expression after an ischemia/ reperfusion injury and that this expression profile was mainly associated with neurons in the infarcted cortex rather than glia cells. It was also shown that HSPB1 and HSPB5 were phosphorylated after ischemia, proposing that phosphorylation can affect their neuroprotective role (Bartelt-Kirbach et al., 2017). Moreover, HSPs have been found to be associated with toxic protein accumulations in protein-misfolding neurodegenerative diseases like AD, PD, and HD. HSPB1 and HSPB5 were detected in senile plaque-associated astrocytes in the brain of patients with AD (Wilhelmus et al., 2006a). Moreover, an in vitro binding of HSPB1 to hyperphosphorylated tau, purified from AD brain, has also been observed (Shimura et al., 2004). HSPB5 was shown to co-localize with $a$-synuclein in the Lewy bodies and to strongly inhibit the elongation of the a-synuclein fibrils (Waudby et al., 2010). Swaroop et al. described an elevated expression for HSPD1 and Il-1 $\beta$ in a study which performed gene expression analysis on human brain samples affected with various CNS diseases such as AD, PD, stroke, or infections (Swaroop et al., 2018).

HSPs have been shown to be neuroprotective in many acute and chronic pathological conditions affecting the brain; therefore, they are considered as potential therapeutic targets (reviewed in: Tóth et al., 2015; Penke et al., 2018; Carra et al., 2019). For example, induced expression of HSPA1 in APP/PSEN1 mice decreased the level of inflammatory cytokines (Sun et al., 2017), whereas transgenic overexpression of HSPA1 or HSPB1 in mouse models of $\mathrm{AD}$ was able to reduce $\mathrm{A} \beta$ plaque formation and cognitive dysfunctions (Hoshino et al., 2011; Tóth et al., 2013) In addition, HSPB8 can promote motor neuron survival by diminishing the toxic effects of dipeptide repeat proteins (Cristofani et al., 2018; Zhu and Reiser, 2018). Current studies revealed that the inhibition of HSPC1 can ameliorate the symptoms of neurodegenerative diseases through inducing the activation of HSF1 and HSPA1, as well as the clearance of protein aggregates (Thirstrup et al., 2016; Wang et al., 2017). Elevated levels of small HSPs are able to ameliorate neuronal cell death under acute brain-damaging conditions as well, like cerebral ischemia and ethanol administration (Tóth et al., 2010; van der Weerd et al., 2010; Arac et al., 2011). Furthermore, HSPA1 overexpression improved the outcome of stroke by preventing neuronal apoptosis (Kim et al., 2016).

As molecular chaperones, the main role of HSPs is to suppress the aggregation of misfolded toxic proteins, which can explain their protective effects in protein-misfolding disorders, like AD or PD. HSPB1 and HSPB5 were found to bind to A $\beta$, inhibiting its fibril formation, therefore reducing its cytotoxic effect in cerebrovascular cell culture in vitro (Wilhelmus et al., 2006b). HSPB1 and HSPB5 were also shown to interact with the aggregation-prone $\alpha$-synuclein to prevent its aggregation in vitro (Cox et al., 2016). Baughman et al. revealed that both HSPB1 and HSPA8 are able to prevent the formation of toxic tau fibrils. HSPB1 can transiently interact with tau during the early phase of fibril formation, while HSPA8 binds to tau tightly at later stages (Baughman et al., 2018). This data indicates that these HSPs might complement each other's function under stress conditions. To restore protein homeostasis, HSPs can also aid the degradation of misfolded proteins via the ubiquitin-proteasome system or by autophagy, to prevent their accumulation in the brain. According to earlier results, under ischemia-induced hypoxia, the level of chaperone-mediated autophagy, which specifically degrades the HSPA8 target proteins, was enhanced which was beneficial for cell survival (Dohi et al., 2012). Another study describes HSPB8 and HSPA8 as part of a multiprotein complex responsible for selectively removing aggregated proteins in amyotrophic lateral sclerosis (Crippa et al., 2010). It was demonstrated that the collaboration between HSPB8 and the co-chaperone BAG3 can enhance autophagy and thereby increase the clearance of protein inclusions produced in motor neuron diseases (Crippa et al., 2016). 
Aside from their classical chaperone function, it has been shown that HSPs have multiple functions within a cell (Horváth et al., 2008; Lanneau et al., 2008; Miller and Fort, 2018). In addition to their central role in the regulation of protein homeostasis, HSPs may exert neuroprotection through several non-chaperone functions (Tóth et al., 2015). For example, neuronal cultures from the hippocampus of mice overexpressing HSPB5 were shown to be able to sustain their dendritic structures upon heat shock (Bartelt-Kirbach et al., 2016) suggesting a role in preserving the dendritic structure and neuronal connectivity upon stress. Numerous data confirm that HSPs can also protect cells against oxidative stress, which is increased in acute and chronic neurodegenerative conditions. This function of HSPs seems to be independent of their antiaggregation effect in certain cases (Wyttenbach et al., 2002). Moreover, HSPs have been demonstrated to inhibit apoptotic cell death cascades triggered by toxic, aggregation-prone proteins, like $\alpha$-synuclein or A $\beta$ (Zourlidou et al., 2004, Yurinskaya et al., 2015). HSPs can also exert their beneficial role through the protection of the $\mathrm{BBB}$, the damage of which was associated with many CNS diseases (Sweeney et al., 2019). HSPB1 expressed in endothelial cells prevented the $\mathrm{BBB}$ disruption and immune cell infiltration by stabilizing the junctional proteins and inhibiting actin polymerization after ischemia (Shi et al., 2017). Moreover, phosphorylated recombinant HSPB1, which was administered intravenously after ischemic injury, was also found to be effective in preventing severe BBB damage (Shimada et al., 2018).

All these activities of HSPs could have an alleviating effect on the pro-inflammatory milieu associated with neurological diseases. By the reduction of neuronal cell death and protein aggregation, HSPs might preclude the initiation of inflammation. By preserving the integrity of the $\mathrm{BBB}$, they might constrain the infiltration of peripheral immune cells. However, an emerging number of evidence support that HSPs, especially extracellular HSPs, directly interact with immune cells. The next chapter of the review is aiming to describe this phenomenon in more detail.

\section{Extracellular HSPs}

Historically HSPs have been regarded as intracellular molecules but, in the last decades, it was revealed that they can also occur in the extracellular space (reviewed in: van Noort et al., 2012; Giuliano et al., 2011; De Maio and Vazquez, 2013; Calderwood, 2018; Reddy et al., 2018). Many different cell types have been shown to be able to secrete HSPs. The first studies describing extracellular HSPs were performed on squid glial cells (Tytell et al., 1986) and rat embryonal cell cultures (Hightower and Guidon, 1989). Tumor cells also secrete high amount of HSPA5 (Kern et al., 2009), HSPC3 (Suzuki and Kulkarni, 2010), or HSPB1 (Stope et al., 2017), and HSPB5 was detected in the media of cultured human adipocytes as well (Lehr et al., 2012). Thermal stress has been demonstrated to increase the amount of secreted HSPA1 from astrocytes (Taylor et al., 2007) and HEPG2 cells (Vega et al., 2008). Moreover, a recent study showed the release of phosphorylated HSPB1 from aggregating human platelets (Tokuda et al., 2018). Therefore, we can suppose that stress protein release may have important regulatory roles under physiological and pathological conditions (Calderwood et al., 2007). One possible mechanism of HSP release is the lysis of damaged, necrotic cells. Several HSPs such as HSPA1, HSPC1, DNAJ, or HSPB1 were found in the supernatant of E.G7 mouse T-lymphocytes (Basu et al., 2000) or HeLa cells (Saito et al., 2005) after the induction of necrotic cell death by freeze-thaw cycles. First, it was assumed that this is the only way for HSPs to be released from a cell. If we suppose that necrotic cells are the main source of extracellular HSPs, the presence of HSPs in the extracellular environment would indicate tissue damage. However, this cannot explain the selective release of HSPs even under non-lethal, mild stressful conditions when cell death is not significantly present. For example, a physiological, fever range heat treatment was able to induce HSPA1 release from prostate carcinoma cells (Mambula and Calderwood, 2006). Cardiac myocytes secrete HSPD1 even under unstressed conditions; however, a mild hypoxic stress further increased the amount of HSPD1 released without signs of necrotic cell death (Gupta and Knowlton, 2007). Similarly, HSPA1 was secreted by purified human peripheral blood mononuclear cells under normal culture conditions and after heat treatment with a barely detectable cell damage (HunterLavin et al., 2004). The mechanism of active, controlled release of HSPs is unclear as they have no secretion leader signal in their sequence and inhibitors of the classical protein transport, and secretory pathways cannot prevent HSP secretion. For example, brefeldin A which is able to block protein transportation from the endoplasmic reticulum to the Golgi seemed to be ineffective in arresting HSP release either in the above mentioned studies (Hunter-Lavin et al., 2004; Gupta and Knowlton, 2007) or in heat-shock-treated Caco-2 cells (Broquet et al., 2003). In contrast, HSPA 1 release was inhibited by methyl- $\beta$-cyclodextrin, a chemical that has membrane raft-disrupting effect suggesting that the association of HSPA1 with lipid rafts is necessary for its secretion (Broquet et al., 2003; Hunter-Lavin et al., 2004). Indeed, several non-traditional secretory mechanisms were proposed to explain the regulated release of HSPs. Methylamine treatment has been demonstrated to block HSPA1 export in different cell types. As this compound can increase intra-lysosomal $\mathrm{pH}$, it was proposed that the HSP secretion might be mediated by secretory lysosomes (Hunter-Lavin et al., 2004; Mambula and Calderwood, 2006). This was also supported by the observation that heat shock stimulates lysosomal exocytosis and increases the HSPA1 level in the lysosomal fraction (Mambula and Calderwood, 2006). Co-localization of HSPB1 with a lysosomal marker suggests that this sHSP can also be secreted through the lysosomal pathway (Rayner et al., 2008; Lee et al., 2012a). As the inhibition of exosomal release from cultured cells was shown to inhibit the secretion of HSPs, exosomes can be considered as another potential carriers for extracellular HSPs (Gupta and Knowlton, 2007; Rayner et al., 2009). These small cellderived vesicles are generated constitutively by many cell types, like immune cells; however, their release is further increased in response to cellular interactions or stress conditions. By transferring lipids, cytosolic proteins, or RNAs from the donor cells, these vesicles can influence the function of acceptor cells; therefore, they have important roles in cell-cell communication (Campanella et al., 2014; Edgar, 2016). Until today, many studies 
confirmed the presence of different HSPs in exosomal vesicles released by cancer cells (Chalmin et al., 2010; McCready et al., 2010; Stope et al., 2017), primary cortical astrocytes (Nafar et al., 2016), or by human retinal pigment epithelial cells (Sreekumar et al., 2010). However, it still remains unclear if HSPs are only cargo materials in exosomes or they also can act as targeting molecules toward the host cells by being localized on the exosomal surface. When HSPs were observed to be present only in the lumen of exosomes, there was no observable interaction between them and the surface receptors of the target cell (Clayton et al., 2005). In this case, the exosome-delivered HSPs cannot interact directly with the target cells only if the vesicles "burst" outside of the cell or fuse with the cell membrane, releasing HSPs into the extracellular space or into the cytosol, respectively (De Maio and Vazquez, 2013). On the other hand, other studies found HSPs in a membrane-bound state in exosomes. For example, HSPA1 has been demonstrated to leave heat-shock-treated HEPG2 cells in a membrane-associated form (Vega et al., 2008). Also, in primary rat cortical astrocytes, $A \beta$ induced the exosomal release of HSPB1, which was associated with the membrane of the exosomes (Nafar et al., 2016). Tumor cell-derived exosomes were found to express HSPA1 on their surface (Gastpar et al., 2005; Chalmin et al., 2010) which makes it possible to stimulate the target cells through surface HSP receptors.

Therefore, it seems that HSPs are released continuously even from unstressed cells. Under stress conditions, cells respond to injury with a strong increase of HSP expression to cope with stressinduced impairments like protein denaturation or apoptosis. At the same time, cellular stress promotes a subsequent release of HSPs into the extracellular space (Calderwood et al., 2007). Accordingly, many reports demonstrated the increased level of HSPs in body fluids after different stress insults and pathological conditions (Quintana and Cohen, 2005; De Maio and Vazquez, 2013; Reddy et al., 2018). HSPD1 levels in the serum are increased in both temporal lobe epilepsy patients and in the animal model of the disease in response to seizures, suggesting that plasma HSPD1 can be used as a biomarker reflecting neuronal cell death (Gammazza et al., 2015). Elevated serum HSPD1 is also related to the severity of both acute and chronic heart failures (Bonanad et al., 2013). HSPA1 level in the blood seems to be a useful biomarker for the detection of different tumor types such as pancreatic cancer (Dutta et al., 2012) as well as head and neck squamous cell carcinoma (Gehrmann et al., 2014). Moreover, the serum level of HSPA1 is increased in diabetic patients and correlates with the severity of the disease (Nakhjavani et al., 2010). Extracellular small molecular weight HSPs have also been associated with different pathological states, as HSPB1 has been detected in the serum of patients with several types of cancer, such as breast cancer (Fanelli et al., 1998; Banerjee et al., 2011), hepatocellular carcinoma (Feng et al., 2005), gastric adenocarcinoma (Huang et al., 2010), colon cancer (Thuringer et al., 2015), or pancreatic carcinoma (Melle et al., 2007; Liao et al., 2009). Plasma HSPB1 level is increased in chronic pancreatitis (Liao et al., 2009), and during acute ischemic stroke conditions (Gruden et al., 2013). Myocardial cells were further observed to release HSPB1 after ischemia (Jin et al., 2014). Lesion size after stroke was found to be strongly correlated with serum HSPB5 levels in a human study, however, interestingly only in younger patients, suggesting that this response is age-dependent (Arac et al., 2011). Extracellular HSPs which are released from infected, damaged, or stressed cells are able to trigger immune response by activating many cells of the innate and adaptive immune systems and can act as local "danger signals" that promote stress response programs in surrounding cells.

\section{Heat-Shock Proteins and Inflammation Modulation}

Extracellular HSPs were shown to have a relatively distinct role from what was observable as their intracellular action. Although, the transmission of HSPs between cells was shown to contribute to the maintenance of normal proteostasis under non-stress conditions (Takeuchi et al., 2015), HSPs are released more substantially from cells under stress conditions. The first observation describing the presence of extracellular HSPs was already associated with stress when a distinct transfer of HSP like proteins was described from glial cells to the axon of neuronal cells upon heat stress, in a squid model system (Tytell et al., 1986). This study was also among the first to suggest a neuroprotective role of stress proteins in the nervous system. Later, this phenomenon was shown to be true for mammalian cells because human glioblastoma cells were also shown to secrete a large amount of HSPA1, and human neuroblastoma cells were described to take up exogenously added, purified HSPA1 which conferred the neuronal cells with an elevated resistance against heat stress and apoptosis (Guzhova et al., 2001). Evidence from studies into intracellular HSPA1 points toward the conclusion that intracellular HSPA1 can exert an anti-inflammatory effect in the brain. A study conducted with mice overexpressing HSPA1 showed that, during ischemic conditions, HSPA1 could exert an anti-inflammatory action by the reduction of NF- $\kappa \mathrm{B}$ activity (van Eden et al., 2005). Another study also suggested a similar action for HSPA1 during ischemia as it was able to interfere with the activation of NF- $\kappa \mathrm{B}$ by inhibiting the phosphorylation I $\kappa \mathrm{B}$ by I $\mathrm{B}$ kinase (IKK) (Zheng et al., 2008). This was also associated with the reduction of microglia-mediated cell death of astrocytes. Moreover, decreased DNA-binding activity of NF- $\mathrm{BB}$ was found in an HSPA1 overexpressing mouse microglial cell line in response to TNFa treatment (Sheppard et al., 2014). In contrast to the notion that HSPB1 is traditionally viewed as a chaperone responsible for acting as a holdase to hand over destabilized proteins for the ATP-dependent chaperone system, intracellular HSPB1 also provides protection against apoptosis by inhibiting mitochondrial apoptotic pathways and by facilitating the activation of NF-kB (Concannon et al., 2003; Guo et al., 2009). In microglial cells, HSPB1 was shown to inhibit the activation of NF-kB and decrease microglial TNF- $\alpha$ production by promoting the lysosomal degradation of IKK $\beta$ by chaperone-mediated autophagy (Liu et al., 2018b). HSPB1 was also associated with an intracellular anti-inflammation modulatory function in epithelial cells, where HSPB1 was able to associate with the IKK $\beta$ and IKKa and inhibit their activity thereby suppressing NF- $\mathrm{KB}$ activation (Kammanadiminti and 
Chadee, 2006). This evidence implies that extracellular HSPs, after being taken up by the target cell, may act through a similar mechanism which would confer resistance to recipient cells in the brain. As mentioned previously, extracellular vesicles may fuse with the membrane of target cells, releasing the HSPs which are in their lumen into the cytosol of the target cell (De Maio and Vazquez, 2013). Therefore, it can be assumed that, similarly to intracellular ones, HSPs from extracellular origin might have neuroprotective, anti-apoptotic, and anti-inflammatory effects.

On the other hand, extracellular HSPs, either released passively from necrotic cells or secreted actively and presented on the surface of extracellular vesicles, can bind to several receptors of the target cells, influencing immune functions. Indeed, many in vitro studies confirmed that the treatment of different cell types with exogenous HSP preparations has an impact on the cytokine response. HSPA1 treatment of LPS-activated monocytes decreased the level of TNF- $\alpha$ and IL-6 (Ferat-Osorio et al., 2014). Interestingly, addition of extracellular HSPA1 to bone marrow-derived murine dendritic cells resulted in a reduced basal level of TNF- $\alpha$ and IFN- $\gamma$ (Borges et al., 2013). In contrast, other evidence implies an opposite pro-inflammatory role for extracellular HSPA1 as it has been described to promote inflammation by the activation of NF- $\mathrm{BB}$ and the stimulation of human macrophages to secrete pro-inflammatory cytokines TNF- $\alpha$, IL- $1 \beta$, and IL-6 (Asea et al., 2000). Exogenous HSPA1 can increase the production of IL- 6 and TNF- $\alpha$ in a concentrationdependent manner in rat microglial culture as well (Kakimura et al., 2002). Moreover, extracellular HSPA1 and HSPC1 are involved in the activation of the adaptive immune response. By sequestering antigenic molecules, they can help their transfer to antigen presenting cells and their load onto MHC molecules (reviewed by Calderwood et al., 2007; van Noort, 2008; Zininga et al., 2018). Compared to HSPA1, the functions of other extracellular HSPs, like sHSPs, are relatively less well defined despite the fact that they are detected to be present in the extracellular environment. Among these proteins, sHSPs are intriguing targets to study in the neurobiological context since they have already been implicated to act as neuroprotective agents in several conditions intracellularly. Considering that HSPB1 has been associated with the transcription factor NF-kB in many studies, it is tempting to speculate that, among the sHSPs, HSPB1 could exert an extracellular control over inflammatory processes in the brain. The extracellular release of HSPB1 has been suggested to have a role in modulating the immune response around the cell, as extracellular HSPB1 was found to activate NF- $\kappa B$ in macrophages (Salari et al., 2013) and myocardial cells (Jin et al., 2014). HSPB1 has been demonstrated to increase the level of IL- 8 while inhibiting the production of TGF- $\beta 1$ CD40 ligand in astrocytes in vitro (Bruinsma et al., 2011). The treatment of microglia cultures with $\alpha$-crystallin resulted in the activation of the cells and increased the production of nitric oxide and TNFa (Bhat and Sharma, 1999). On the other hand, another study showed that $\alpha$-crystallin pretreatment can reduce the level of the same molecules induced by LPS in primary rat microglial cell culture (Wu et al., 2009). Moreover, it effectively reduced astrocyte activation in vitro, in response to LPS treatment (Masilamoni et al., 2006).
These results clearly show that HSPs are involved in the regulation of immune responses in different organs, including the brain. However, whether their exact effect is anti- or pro-inflammatory, it depends on many factors (Figure 2). An interesting observation came from by Basu et al. that necrotic but not apoptotic cells are able to release HSPA1, HSPC1, and calreticulin which were found to be immunestimulatory through the activation of antigen-presenting cells via the NF- $\mathrm{BB}$ pathway (Basu et al., 2000). This result suggests that the effect of the released HSP is highly dependent on the state of the donor cell and the cellular processes taking place therein. For example, as described in the "extracellular HSP" section, aside from the active vesicular secretion, HSP could be excreted passively, by necrosis. The emergence of the seemingly contradicting observations describing HSPA1 both as a pro- and an anti-inflammatory agents have led to the hypothesis that the context as to how HSPA1 (and possibly other HSPs) reaches the extracellular environment matters in regard to their modulatory action on inflammation (Broere et al., 2011; van Eden et al., 2012). However, probably not the donor cell's state is the only factor that can influence the effect of HSPs. Similarly, as was proposed in the case of heat treatment (Lee and Repasky, 2012), we can suppose that the HSPs themselves might have diverse effects based on the status of the recipient cell.

Moreover, several receptors have been characterized for HSPs which can all turn on specific signaling pathways. This suggests that the anti- or pro-inflammatory roles of HSPs are strongly dependent on their cell surface receptors as well. HSPs exert their immunomodulatory functions on macrophages, dendritic cells, T cells, B cells, and NK cells via many different receptors (reviewed in Quintana and Cohen, 2005; Calderwood et al., 2016). For example, CD91, CD40, and the chemokine receptor CCR5 have been demonstrated to interact with HSPA1 (Basu et al., 2001; Becker et al., 2002; Pido-Lopez et al., 2007), of which CD40 and CCR5 are expressed on the surface of microglial cells. Scavenger receptors such as LOX-1 and SREC-1 can act as receptors not only for HSPA1 but for HSPD1 and HSPC1 as well (Thériault et al., 2006; Murshid et al., 2010; Xie et al., 2010a). Two members of the TLR family, namely, TLR 2 and TLR4, are considered as HSP receptors; however, their specific interactions have hitherto been questioned. As the same receptors are responsible for the detection of bacteria-derived danger signals, like LPS, it seems to be possible that the cytokine induction was not caused by the HSPs themselves rather by the co-purified bacterial endotoxins (reviewed in Quintana and Cohen, 2005; van Noort, 2008; Kim and Yenari, 2013). However, later several studies demonstrated that non-bacteria-derived HSP preparations can also induce macrophage activation (Basu et al., 2000; Wang et al., 2006; Vega et al., 2008). These studies also draw attention to the probability that sequestering of different molecules by HSPs could play a role in their physiological immunomodulating effect. HSPs are able to bind to a broad array of molecules from bacterial LPS to tumor-derived peptides, augmenting their immunogenicity (Quintana and Cohen, 2005). This was confirmed by a study demonstrating that HSPD1 and HSPA1 alone were inefficient to induce the TNF- $\alpha$ secretion of human peripheral blood-derived mononuclear cells; however, they can potentiate LPS-induced 


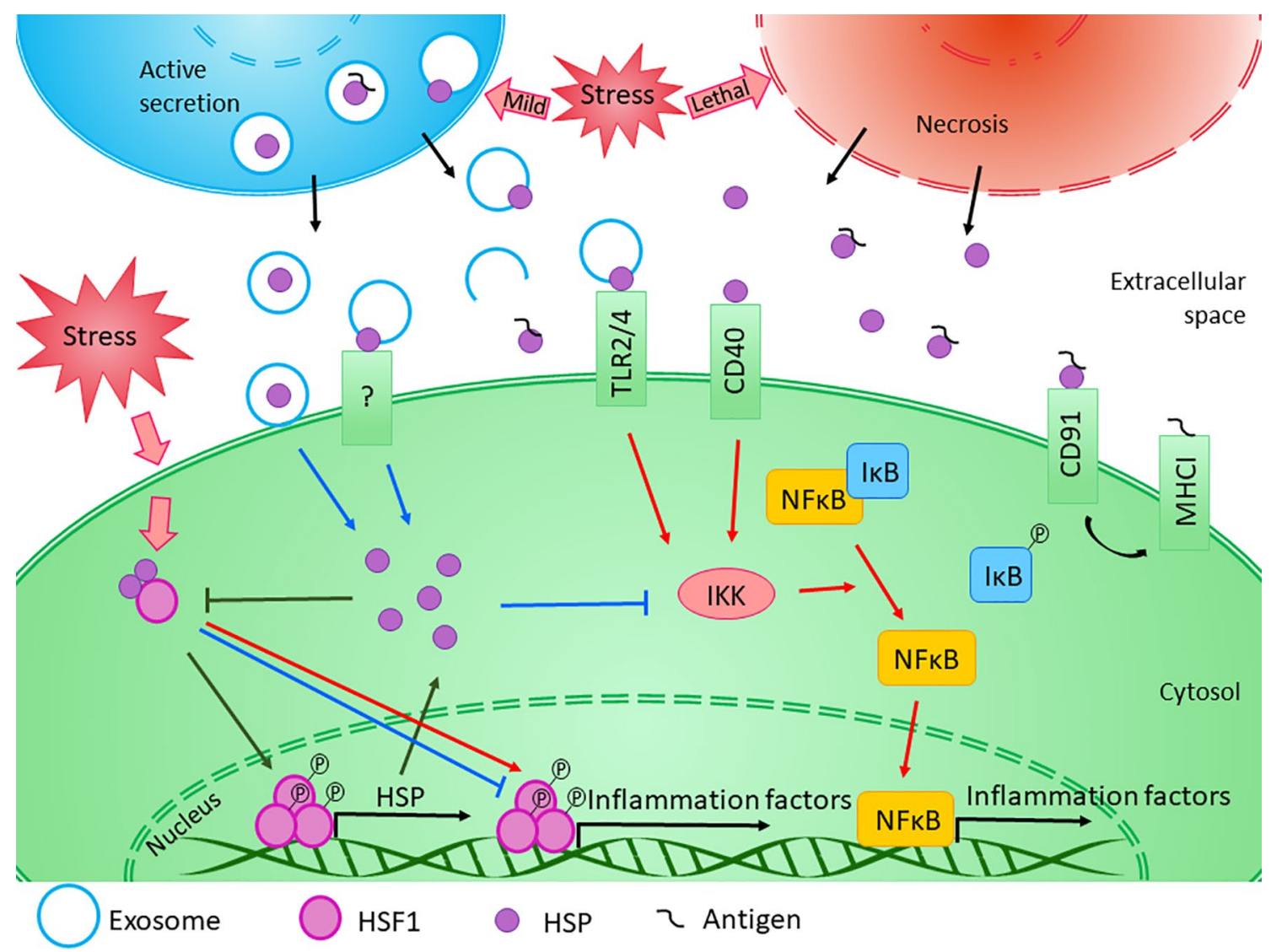

FIGURE 2 | Diverse effects of HSPs on inflammation. The exact role of HSPs in the regulation of innate and adaptive immune responses is influenced by several factors. Transcription of HSP genes is regulated by HSF1, which normally presents in the cytosol in its inactive form bounded to HSPs. Under stress conditions, the monomeric HSF1 dissociates from HSPA/C, trimerizes, and subsequently translocates to the nucleus, where it upregulates the expression of HSPs. Moreover, HSF1 was suggested to have bi-directional effect on the expression of inflammatory factors. HSF1 was shown to inhibit the expression of TNF- $\alpha$ by binding to its promoter, while it was also able to activate TNF- $\alpha$ as part of a multiprotein complex. Similarly, HSF1 was found to bind directly to IL-6 promoter opening of the chromatin structure thereby facilitating the access of activator or repressor molecules. The newly synthesized intracellular HSPs have protective and anti-apoptotic effects. Both HSPB1 and HSPA1 were shown to inhibit the activation of NF-kB by inhibiting IKK, thereby exerting an anti-inflammatory function. At the same time, cellular stress promotes the release of HSPs into the extracellular space. Lethal stress leads to the passive secretion of HSPs from necrotic cells, which usually induce a strong pro-inflammatory activity. On the other hand, HSPs can be secreted actively even under non-lethal, mild stress conditions. Although the classical protein secretory pathways are not secreting HSPs, alternative secretory mechanisms, such as exosomal release can be the basis of their regulated export. HSPS were found in the lumen of exosomal vesicles or they can occur in a membrane-associated form. Luminal HSPs cannot interact directly with the target cells only if the vesicles "burst" outside of the cell or fuse with the cell membrane, releasing HSPs into the extracellular space or into the cytosol. HSPs presented in the membrane of extracellular vesicles can bind to various surface receptors, such as toll-like receptors, that can induce the NF-kB pathway. Moreover, by sequestering antigenic molecules, HSPs are involved in antigen presentation. On the other hand, many studies confirmed that exogenous HSPA1 and HSPB1 exert antiinflammatory effects through yet undefined mechanism in different pathological conditions. (Reviewed in van Noort, 2008; De Maio and Vazquez, 2013; Kim and Yenari, 2013). Red arrows denote pro-inflammatory, while blue arrows denote anti- inflammatory processes.

TNF- $\alpha$ release when added $24 \mathrm{~h}$ prior to the stimulation (Bangen et al., 2007). It is likely, that other, yet uncharacterized receptors exist through which the immunomodulatory effects of HSPs could be mediated. Furthermore, the combinatorial effect of the different cell surface receptors might influence the exact pro-or anti-inflammatory role of certain HSPs (Calderwood et al., 2016).

It is also important to note that based on changes in the amount of a single cytokine, it is not possible to determine clearly if a process is pro- or anti-inflammatory. For example, TNF- $\alpha$ seems to have a dual role in neuroinflammation and can be involved in both pro- and anti-inflammatory response profiles (van Noort et al., 2012). Therefore, measuring the levels of only a few cytokines in a certain isolated cell line is probably not sufficient to determine the overall biological effect of a treatment (van Noort et al., 2012). The situation is further complicated by the fact that the inflammatory process itself may have beneficial and harmful outcomes as well. Therefore, to determine the role of HSPs in inflammatory brain diseases, we should take into consideration several symptoms not only the level of inflammatory factors.

Results suggest that exogenously added HSPs have a general anti-inflammatory effect in different acute brain injuries. Several evidences support the potential neuroprotective role of extracellular HSPA1 since it was described to inhibit motor and sensory neuronal cell deaths after traumatic nerve injury 
(Tidwell et al., 2004) and to preserve synaptic transmission during hyperthermic conditions (Kelty et al., 2002). The exogenous addition of HSPA8 was also shown to prevent axotomy-induced death of sensory neurons (Houenou et al., 1996). The injection of recombinant HSPB1 exerted a protective effect against ischemic injury and decreased inflammation in the brain during these processes (Shimada et al., 2018). Apart from HSPB1, another sHSP, HSPB5 was also described to have an anti-inflammatory role when applied extracellularly whereby it acted against pathologic CNS inflammation in autoimmune demyelination and ameliorated experimental autoimmune encephalomyelitis in mice (Ousman et al., 2007). Intraperitoneal injection of recombinant HSPB5 was able to reduce lesion size and modulate the peripheral inflammatory response, even when the treatment was started $12 \mathrm{~h}$ after stroke onset (Arac et al., 2011). HSPB4/ B5 isolated from bovine lens prevented the elevation of GFAP and NF- $\mathrm{B}$ expression induced by acute inflammation in the brain of silver nitrate-treated mice (Masilamoni et al., 2006). Intravitreal injection of $\alpha$-crystallin decreased the expression of TNFa and iNOS after optic nerve injury in vivo in rats (Wu et al., 2009). In contrast, the intrathecal injection of HSPD1 activated the TLR4 pathway which resulted in neurodegeneration and demyelination (Rosenberger et al., 2015). Furthermore, another microglial receptor, LOX-1, was described to bind to HSPD1 and to promote a deleterious inflammatory process (Zhang et al., 2012). HSPD1 is originally localized to the mitochondria but, in the case of brain injury, it was also found to be present in the extracellular space. This extracellular presence is due to the fact that, during CNS disorders, mitochondria dysfunction occurs, leading to the abnormal distribution of HSPD1 (Cappello et al., 2010). The extracellular HSPD1 can serve as a danger signal, and in cell cultures, it was shown to induce neuronal damage which was associated with the TLR4-MyD88 signaling pathway in microglia cells (Lehnardt et al., 2008).

Numerous evidences support the protective role of HSPs in chronic neurodegenerative diseases in vivo, especially in proteinmisfolding disorders, described briefly in the section "HSPs and their role in CNS diseases." However, most of these studies were performed on transgenic animals overexpressing different HSPs, or the increased expression of HSPs was induced by drug treatment. Therefore, it is difficult to separate the specific effects of intra- and extracellular HSPs, although one can suppose that both are involved in ameliorating the symptoms. For example, in a Drosophila model, it was demonstrated that HSPA, secreted into the extracellular space, can bind to $A \beta$ reducing its neurotoxic effect and therefore the level of cell death (FernandezFunez et al., 2016). In contrast, it is difficult to find studies in which exogenously added HSPs are used to treat chronic neurodegenerative diseases in animal models. Nonetheless, several results suggest that the neuroprotective effect of HSPs is partly based on their ability to influence the function of immune cells. Microglial cells activated by exogenous HSPA1 or HSPC1 showed an elevated capacity for $A \beta$ phagocytosis suggesting that extracellular HSPs might facilitate the clearance of these misfolded proteins (Kakimura et al., 2002). This effect of HSPC1 was confirmed later in vivo as well, by the simultaneous intrahippocampal injections of A $\beta$ and HSPC1 (Takata et al., 2003).
HSPD1 was also found to stimulate phagocytosis in the N9 murine microglial cell line. Interestingly, this effect was diminished by the downregulation of TREM2 receptor. As HSPD1 was found to bind to TREM2, it is likely that the HSPD1-induced activation of phagocytosis might be mediated through this receptor (Stefano et al., 2009). As the decline of the normal phagocytic activity might have an important role in the pathogenesis of diseases associated with protein misfolding (see details in "Role of neuroinflammation in different acute and chronic CNS diseases" section), the promotion of the engulfment of toxic proteins by microglial cells might be useful in the treatment of these diseases. Therefore, HSPs could be important therapeutic targets in both acute and chronic neurological diseases, not only because of their classical chaperone function, but also considering their ability to modulate inflammatory processes.

\section{Modulation and Application of Heat-Shock Proteins as Potential Therapies Against Chronic Neuroinflammation}

Based on the accumulated evidence reviewed herein, HSPs themselves and compounds modulating the heat-shock response could potentially open up new avenues for inflammation modulation in the nervous system. Approaches to fine-tune the intracellular amount of HSPs and to deliver functional, therapeutic extracellular HSPs to cells are on the rise and would certainly contribute to the panel of medical treatments against inflammation-associated diseases in the nervous system. For this purpose, membrane lipid therapy seems to be a promising solution, as membrane fluidity and microdomain organization are involved in the regulation of the cellular heat-shock response. For example, manipulating membrane lipid composition can influence the release, and therefore the immune stimulatory effects, of HSPs (Vigh et al., 2007). An emerging number of studies are describing the manipulation of HSPs by chemical means (Török et al., 2014). HSP co-inducers were already successfully applied in mice against hypoxia-induced brain damage (Xu et al., 2011), chemotherapy-induced peripheral neuropathy in rats (Bárdos et al., 2003), and were shown to have neuroprotective effects in a mouse model of AD (Kasza et al., 2016). Arimoclomol, a drug which acts like an HSP co-inducer, was suggested as a candidate for the therapy of amyotrophic lateral sclerosis as it can improve hind limb muscle function and motoneuron survival in a mouse model of the disease (Kieran et al., 2004; Phukan, 2010). Arimoclomol was also been demonstrated to have a beneficial effect against the neuronopathic form of Gaucher disease, by the induction of the HSPA5 (Fog et al., 2018). The pharmacological enchantment of the unfolded protein response and the heat-shock response by arimoclomol also provided protection against retinal degeneration in the animal model of rhodopsin retinitis pigmentosa (Parfitt et al., 2014). It is important to note that arimoclomol was described to be nontoxic in a double-blind, placebo-controlled trial in which patients with amyotrophic lateral sclerosis received the drug (Benatar et al., 2018). BRX-220, another HSP co-inducer, was shown to protect motoneurones from axotomy-induced cell death and affect the upregulation of HSPC1 and HSPA1 in parallel, in glia 
and neuron cells (Kalmar et al., 2002). The same compound was also observed to be effective in the prevention against peripheral neuropathy (Kürthy et al., 2002) and to promote restoration of morphological and functional properties in the sensory system following peripheral nerve injury (Kalmar et al., 2003).

Geranylgeranylacetone, an HSP inducer, was demonstrated to alleviate cerebral ischemic damage in the brains of rats (Uchida et al., 2006). Similar observations were made with respect to a-lipoic acid, a heat-shock response activator, in the gerbil brain following ischemic stress (Lee et al., 2012b). Pharmacological induction of HSPA 1 in microglia and neurons by $17-\mathrm{N}$-allylamino17-demethoxygeldanamycin (17-AAG) was shown to reduce the volume of hemorrhage and improve neurobehavioral outcomes in a mouse model of experimental traumatic brain injury (Kim et al., 2015). Another HSP inducer celastrol, a chemical compound isolated from the Celastracea family of plants, was identified to induce the phosphorylation and DNA binding of HSF1, which consequently can result in the upregulation of several HSPs (Westerheide et al., 2004). The fact that celastrol can activate heat-shock gene transcription alone or synergistically with other stresses or compounds makes it a promising adjuvant drug candidate (Westerheide et al., 2004). Celastrol treatment was shown to increase the expression of HSPA1 and reduce the levels of TNF- $\alpha$ in spinal motor neurons and contribute to motor neuron survival in the SOD1(G93A) transgenic mouse model of amyotrophic lateral sclerosis (Kiaei et al., 2005). Other drugs with herbal origins have been also shown to act like HSP inducers. Paeoniflorin, a monoterpene glycoside, was characterized to induce HSP through the activation of HSF1 and the formation of HSF1 containing granules in the nucleus (Yan et al., 2004). The treatment of rats with paeoniflorin can protect the brain from cerebral ischemic injury via inhibition of apoptosis (Zhang et al., 2015). Glycyrrhizin a triterpenoid saponin was also suggested to be an HSP co-inducer (Yan et al., 2004). Several other compounds have been known to have a positive effect on HSP expression such as the hydroxylamine derivative HSP co-inducer bimoclomol (Vígh et al., 1997), the antiulcer drug geranylgeranylacetone (Hirakawa et al., 1996) or the benzoquinone antibiotic herbimycin A (Morris et al., 1996). All of which were being effective against different pathophysiological conditions in the CNS, as bimoclomol proved to be cytoprotective for retinal glia and neuronal cell against diabetes-related ischemic cell damages (Bíró et al., 1998), while geranylgeranylacetone is described to be neuroprotective against traumatic brain injury (Zhao et al., 2013), and herbimycin A treatment was capable to induce sympathetic neuron survival and to protect against hypoxia-induced neuronal damage (Cabralda-Silva et al., 2003).

Aside from the pharmacological modulation of their intracellular expression levels, HSPs themselves can be used as therapeutic agents, as described by several studies. Purified HSPA1/ HSPA8 proteins injected into the third ventricle of the brain were found to infiltrate into the cytosol of the neurons in different brain regions. In parallel, the treatment was able to decrease the duration and severity of chemically induced seizures and reduce muscle tonus (Ekimova et al., 2010). Similarly, intranasally injected human HSPA1 rapidly penetrate into the brain showing mainly intracellular localization (Bobkova et al., 2014). Furthermore, exogenous recombinant HSPA1 ameliorates symptoms of $\mathrm{AD}$ such as $A \beta$ accumulation and memory deficits (Bobkova et al., 2014) and improves cognitive functions and increases lifespan of old mice (Bobkova et al., 2015). The administration of recombinant HSPA1 to glioblastoma cells within the brain of rats has also shown to alter the inflammatory environment within the surrounding region of the tumor as it has induced the activation and IFN $\gamma$-secretion of CD8+ cells (Shevtsov et al., 2014). These studies are highlighting the therapeutic potential of the exogenous delivery of recombinant HSPs into the nervous system. However, the delivery and targeting of these molecules into the specific brain regions could present a significant challenge.

The aforementioned and well-characterized interaction of HSPs with membranes (Horváth et al., 2008) might open up new possibilities to come across the biological barriers preventing the efficient delivery of biological molecules to the brain with a goal to achieve the beneficial modulation of inflammatory processes. Several HSPs were found to interact and be inserted into the plasma membrane, as well the release of HSPs to the extracellular environment is associated with membranes (Balogi et al., 2019). Thus, it is plausible that the therapeutic application of membranebound HSPs could significantly enhance their anti- or proinflammatory activity. HSPA1 was described to be released into the extracellular environment upon heat stress in a membraneassociated form originating from the plasma membrane also the membrane-bound HSPA1 showed a significantly higher potential to induce TNF production in macrophages compared to the free recombinant form of the protein (Vega et al., 2008). Similarly, other observations have detected that exosome containing HSPA1 on their surface can stimulate the migration and cytolytic activity of NK cells (Gastpar et al., 2005). Membrane-bound HSPA1 was also associated with the stimulation of a type $1 \mathrm{CD} 4(+)$ helper $\mathrm{T}$ cell and a CD8(+) cytotoxic T lymphocyte response (Xie et al., 2010b).

Extracellular membranous vesicles as exosomes have already been associated with neuroinflammation (Gupta and Pulliam, 2014). The liposomal delivery of protein into the nervous system has also recently been utilized to alleviate inflammatory processes (Vieira and Gamarra, 2016). However, the insertion of proteins to the bilayer is presenting a significant challenge during the preparation of liposomes. This problem can be circumvented by the application of a novel form of nanoparticles termed as membrane nanodisks, where a lipid bilayer is surrounded by an amphipathic protein belt (Rouck et al., 2017). Membrane nanodisks are also showed to be potential vehicle for CNS delivery, as it has been described to cross the BBB and to effectively target glioma cells within the brain (Wang et al., 2018b). The application of these membrane nano-carriers might provide a useful strategy to deliver membrane-bound HSPs to the nervous system. The use of membrane nanodisks in therapy seems to be especially promising in the light of the of the fact that the highly tunable lipid environment could provide a milieu to the membrane-associated proteins which keeps them in solution without the use of detergents and maintain a structure which is more similar to the one they have when associated with biological membranes (Bayburt et al., 1998; Dominik and Kossiakoff, 2015). The reconstruction of a combination of antigens into membrane nanodisks has already been shown to generate protective immunity against viral 
challenge (Bhattacharya et al., 2010) and to raise anti-cancer immunity in mice (Kuai et al., 2017). Thus, the use of these membrane mimicking nanodisks to carry HSPs could provide a potential new formulation for HSP-based therapies.

\section{CONCLUSION}

Immediately after an acute brain injury or infection, inflammation contributes to the efficient immune response, eliminating cellular debris and pathogens as a precursor to permitting tissue repair and regeneration. Similarly, in chronic neurodegenerative diseases, such as protein-misfolding disorders, immune cells can contribute to the elimination of toxic protein aggregates, at least in the initial phase. However, the long duration of the triggering stimuli results in excessive, chronic inflammation and uncontrolled macrophage activation finally contributing to further tissue injury and disease progression. Therefore, inflammatory processes should be tightly regulated to maintain the balance between remediation and the over-activated, harmful effects of the immune cells. Pharmacological manipulation of HSP expression, activity and localization might provide an opportunity to modulate beneficially the inflammatory processes in the brain. Thus, it seems rational to expect that the application of compounds with known HSP modulatory activity gradually will

\section{REFERENCES}

Ali, A., Biswas, A., and Pal, M. (2019). HSF1 mediated TNF- $\alpha$ production during proteotoxic stress response pioneers proinflammatory signal in human cells. FASEB J. 33, 2621-2635. doi: 10.1096/fi.201801482R

Arac, A., Brownell, S. E., Rothbard, J. B., Chen, C., Ko, R. M., Pereira, M. P., et al. (2011). Systemic augmentation of aB-crystallin provides therapeutic benefit twelve hours post-stroke onset via immune modulation. Proc. Natl. Acad. Sci. 108, 13287-13292. doi: 10.1073/pnas.1107368108

Arunachalam, P., Ludewig, P., Melich, P., Arumugam, T. V., Gerloff, C., Prinz, I., et al. (2017). CCR6 (CC chemokine receptor 6) is essential for the migration of detrimental natural interleukin-17-producing $\gamma \delta$ T cells in stroke. Stroke 48, 1957-1965. doi: 10.1161/STROKEAHA.117.016753

Asea, A., Kraeft, S.-K., Kurt-Jones, E. A., Stevenson, M. A., Chen, L. B., Finberg, R. W., et al. (2000). HSP70 stimulates cytokine production through a CD14-dependant pathway, demonstrating its dual role as a chaperone and cytokine. Nat. Med. 6, 435-442. doi: 10.1038/74697

Balogh, G., Péter, M., Glatz, A., Gombos, I., Török, Z., Horváth, I., et al. (2013). Key role of lipids in heat stress management. FEBS Lett. 587, 1970-1980. doi: 10.1016/j.febslet.2013.05.016

Balogi, Z., Multhoff, G., Jensen, T. K., Lloyd-Evans, E., Yamashima, T., Jäättelä, M., et al. (2019). Hsp70 interactions with membrane lipids regulate cellular functions in health and disease. Prog. Lipid Res. 74, 18-30. doi: 10.1016/j.plipres.2019.01.004

Banerjee, S., Lin, C.-F. L., Skinner, K. A., Schiffhauer, L. M., Peacock, J., Hicks, D. G., et al. (2011). Heat shock protein 27 differentiates tolerogenic macrophages that may support human breast cancer progression. Cancer Res. 71, 318-327. doi: 10.1158/0008-5472.CAN-10-1778

Bangen, J. M., Schade, F. U., and Flohé, S. B. (2007). Diverse regulatory activity of human heat shock proteins 60 and 70 on endotoxin-induced inflammation. Biochem. Biophys. Res. Commun. 359, 709-715. doi: 10.1016/j.bbrc.2007.05.167

Banjara, M., and Ghosh, C. (2017). Sterile neuroinflammation and strategies for therapeutic intervention. Int. J. Inflam. 2017, 1-20. doi: 10.1155/2017/8385961

Bárdos, G., Móricz, K., Jaszlits, L., Rabloczky, G., Tory, K., Rácz, I., et al. (2003). BGP-15, a hydroximic acid derivative, protects against cisplatin- or taxolinduced peripheral neuropathy in rats. Toxicol. Appl. Pharmacol. 190, 9-16. doi: 10.1016/S0041-008X(03)00155-8 be tested for their applicability in the field of neuroinflammation. Alternatively, the delivery of HSP proteins to the disease-affected brain regions could also be expected to be exploited in future therapies. However, it is important to note that the full range of cell surface receptors functioning as HSP binding partners is not elucidated yet. Thus, aside from the technological implications of the delivery of the proteins, the proper surface receptor interactions and their physiological consequences should be appropriately evaluated for each brain area.

\section{AUTHOR CONTRIBUTIONS}

$\mathrm{MT}, \mathrm{BD}$, and $\mathrm{BC}$, contributed to the conception and design in the manuscript. MT, $\mathrm{BD}$, and $\mathrm{BC}$ wrote the manuscript. $\mathrm{MT}, \mathrm{BD}$, and $\mathrm{BC}$ reviewed the manuscript. $\mathrm{MT}, \mathrm{BD}$, and $\mathrm{BC}$ prepared the figures. All authors approved the final manuscript.

\section{FUNDING}

This work was supported by funding from the National Research, Development and Innovation Office, Hungary (GINOP 2.3.2.15.2016-00060, GINOP 2.3.2.-15.2016-00040 and GINOP 2.3.2.-15.2016-00001).

Barna, J., Csermely, P., and Vellai, T. (2018). Roles of heat shock factor 1 beyond the heat shock response. Cell. Mol. Life Sci. 75, 2897-2916. doi: 10.1007/ s00018-018-2836-6

Bartelt-Kirbach, B., Moron, M., Glomb, M., Beck, C.-M., Weller, M.-P., and Golenhofen, N. (2016). HspB5/aB-crystallin increases dendritic complexity and protects the dendritic arbor during heat shock in cultured rat hippocampal neurons. Cell. Mol. Life Sci. 73, 3761-3775. doi: 10.1007/s00018-016-2219-9

Bartelt-Kirbach, B., Slowik, A., Beyer, C., and Golenhofen, N. (2017). Upregulation and phosphorylation of HspB1/Hsp25 and HspB5/aB-crystallin after transient middle cerebral artery occlusion in rats. Cell Stress Chaperones 22, 653-663. doi: 10.1007/s12192-017-0794-9

Basu, S., Binder, R. J., Ramalingam, T., and Srivastava, P. K. (2001). CD91 is a common receptor for heat shock proteins gp96, hsp90, hsp70, and calreticulin. Immunity 14, 303-313. doi: 10.1016/S1074-7613(01)00111-X

Basu, S., Binder, R. J., Suto, R., Anderson, K. M., and Srivastava, P. K. (2000) Necrotic but not apoptotic cell death releases heat shock proteins, which deliver a partial maturation signal to dendritic cells and activate the NF- $\kappa \mathrm{B}$ pathway. Int. Immunol. 12, 1539-1546. doi: 10.1093/intimm/12.11.1539

Baughman, H. E. R., Clouser, A. F., Klevit, R. E., and Nath, A. (2018). HspB1 and Hsc70 chaperones engage distinct tau species and have different inhibitory effects on amyloid formation. J. Biol. Chem. 293, 2687-2700. doi: 10.1074/jbc. M117.803411

Bayburt, T. H., Carlson, J. W., and Sligar, S. G. (1998). Reconstitution and imaging of a membrane protein in a nanometer-size phospholipid bilayer. J. Struct. Biol. 123, 37-44. doi: 10.1006/jsbi.1998.4007

Becker, T., Hartl, F.-U., and Wieland, F. (2002). CD40, an extracellular receptor for binding and uptake of Hsp70-peptide complexes. J. Cell Biol. 158, 1277-1285. doi: $10.1083 /$ jcb. 200208083

Benatar, M., Wuu, J., Andersen, P. M., Atassi, N., David, W., Cudkowicz, M., et al. (2018). Randomized, double-blind, placebo-controlled trial of arimoclomol in rapidly progressive SOD1 ALS. Neurology 90, e565-e574. doi: 10.1212/ WNL.0000000000004960

Benraiss, A., Wang, S., Herrlinger, S., Li, X., Chandler-Militello, D., Mauceri, J., et al. (2016). Human glia can both induce and rescue aspects of disease phenotype in Huntington disease. Nat. Commun. 7, 11758. doi: 10.1038/ ncomms 11758 
Bhat, N. R., and Sharma, K. K. (1999). Microglial activation by the small heat shock protein, alpha-crystallin. Neuroreport 10, 2869-2873. doi: 10.1097/00001756-199909090-00031

Bhattacharya, P., Grimme, S., Ganesh, B., Gopisetty, A., Sheng, J. R., Martinez, O., et al. (2010). Nanodisc-incorporated hemagglutinin provides protective immunity against influenza virus infection. J. Virol. 84, 361-371. doi: 10.1128/ JVI.01355-09

Bíró, K., Pálhalmi, J., Tóth, A. J., Kukorelli, T., and Juhász, G. (1998). Bimoclomol improves early electrophysiological signs of retinopathy in diabetic rats. Neuroreport 9, 2029-2033. doi: 10.1097/00001756-199806220-00022

Bobkova, N. V., Evgenev, M., Garbuz, D. G., Kulikov, A. M., Morozov, A., Samokhin, A., et al. (2015). Exogenous Hsp70 delays senescence and improves cognitive function in aging mice. Proc. Natl. Acad. Sci. 112, 16006-16011. doi: 10.1073/pnas.1516131112

Bobkova, N. V., Garbuz, D. G., Nesterova, I., Medvinskaya, N., Samokhin, A., Alexandrova, I., et al. (2014). Therapeutic effect of exogenous Hsp70 in mouse models of Alzheimer's disease. J. Alzheimers Dis. 38, 425-435. doi: 10.3233/ JAD-130779

Bonanad, C., Núñez, J., Sanchis, J., Bodi, V., Chaustre, F., Chillet, M., et al. (2013). Serum heat shock protein 60 in acute heart failure: a new biomarker? Congest. Heart Fail. 19, 6-10. doi: 10.1111/j.1751-7133.2012.00299.x

Borges, T. J., Lopes, R. L., Pinho, N. G., Machado, F. D., Souza, A. P. D., and Bonorino, C. (2013). Extracellular Hsp70 inhibits pro-inflammatory cytokine production by IL-10 driven down-regulation of C/EBP $\beta$ and C/EBP $\delta$. Int. J. Hyperth. 29, 455-463. doi: 10.3109/02656736.2013.798037

Braak, H., Sastre, M., and Del Tredici, K. (2007). Development of alpha-synuclein immunoreactive astrocytes in the forebrain parallels stages of intraneuronal pathology in sporadic Parkinson's disease. Acta Neuropathol. 114, 231-241. doi: 10.1007/s00401-007-0244-3

Brochard, V., Combadière, B., Prigent, A., Laouar, Y., Perrin, A., Beray-Berthat, V., et al. (2009). Infiltration of CD4+ lymphocytes into the brain contributes to neurodegeneration in a mouse model of Parkinson disease. J. Clin. Invest. 119, 182-192. doi: 10.1172/JCI36470

Broere, F., van der Zee, R., and van Eden, W. (2011). Heat shock proteins are no DAMPs, rather "DAMPERs." Nat. Rev. Immunol. 11, 565-565. doi: 10.1038/ nri2873-cl

Broquet, A. H., Thomas, G., Masliah, J., Trugnan, G., and Bachelet, M. (2003). Expression of the molecular chaperone Hsp70 in detergent-resistant microdomains correlates with its membrane delivery and release. J. Biol. Chem. 278, 21601-21606. doi: 10.1074/jbc.M302326200

Brown, M. A., Zhu, L., Schmidt, C., and Tucker, P. W. (2007). Hsp90-from signal transduction to cell transformation. Biochem. Biophys. Res. Commun. 363, 241-246. doi: 10.1016/j.bbrc.2007.08.054

Bruinsma, I. B., de Jager, M., Carrano, A., Versleijen, A. A. M., Veerhuis, R., Boelens, W., et al. (2011). Small heat shock proteins induce a cerebral inflammatory reaction. J. Neurosci. 31, 11992-12000. doi: 10.1523/ JNEUROSCI.0945-11.2011

Buxbaum, J. D., Oishi, M., Chen, H. I., Pinkas-Kramarski, R., Jaffe, E. A., Gandy, S. E., et al. (1992). Cholinergic agonists and interleukin 1 regulate processing and secretion of the Alzheimer beta/A4 amyloid protein precursor. Proc. Natl. Acad. Sci. U. S. A. 89, 10075-10078. doi: 10.1073/ pnas.89.21.10075

Cabral-da-Silva, M. C., dos Santos, N. E. L., de Mello, F. G., Taylor, J. S. H., Tolkovsky, A. M., Linden, R., et al. (2003). Herbimycin A induces sympathetic neuron survival and protects against hypoxia. Neuroreport 14, 2397-2401. doi: 10.1097/00001756-200312190-00022

Caldeira, C., Cunha, C., Vaz, A. R., Falcão, A. S., Barateiro, A., Seixas, E., et al. (2017). Key aging-associated alterations in primary microglia response to beta-amyloid stimulation. Front. Aging Neurosci. 9, 277. doi: 10.3389/fnagi.2017.00277

Calderwood, S. K. (2018). Heat shock proteins and cancer: intracellular chaperones or extracellular signalling ligands? Philos. Trans. R. Soc. B Biol. Sci. 373, 20160524. doi: 10.1098/rstb.2016.0524

Calderwood, S. K., Gong, J., and Murshid, A. (2016). Extracellular HSPs: the complicated roles of extracellular HSPs in immunity. Front. Immunol. 7, 159. doi: 10.3389/fimmu.2016.00159

Calderwood, S. K., Mambula, S. S., Gray, P. J., and Theriault, J. R. (2007). Extracellular heat shock proteins in cell signaling. FEBS Lett. 581, 3689-3694. doi: 10.1016/j.febslet.2007.04.044
Calderwood, S. K., Murshid, A., and Prince, T. (2009). The shock of aging: molecular chaperones and the heat shock response in longevity and aging; a mini-review. Gerontology 55, 550-558. doi: 10.1159/000225957

Campanella, C., Bavisotto, C. C., Gammazza, A. M., Nikolic, D., Rappa, F., David, S., et al. (2014). Exosomal heat shock proteins as new players in tumour cell-to-cell communication. J. Circ. Biomarkers 3, 4. doi: $10.5772 / 58721$

Cappello, F., Di Stefano, A., De Macario, E. C., and Macario, A. J. L. (2010). Hsp60 and Hsp10 in ageing. Dordrecht: Springer, 401-426. doi: 10.1007/978-90-481-3381-9_23

Carnemolla, A., Labbadia, J. P., Lazell, H., Neueder, A., Moussaoui, S., and Bates, G. P. (2014). Contesting the dogma of an age-related heat shock response impairment: implications for cardiac-specific age-related disorders. Hum. Mol. Genet. 23, 3641-3656. doi: 10.1093/hmg/ddu073

Carra, S., Alberti, S., Benesch, J. L. P., Boelens, W., Buchner, J., Carver, J. A., et al. (2019). Small heat shock proteins: multifaceted proteins with important implications for life. Cell Stress Chaperones 24, 295-308. doi: 10.1007/ s12192-019-00979-z

Chalmin, F., Ladoire, S., Mignot, G., Vincent, J., Bruchard, M., Remy-Martin, J.-P., et al. (2010). Membrane-associated Hsp72 from tumor-derived exosomes mediates STAT3-dependent immunosuppressive function of mouse and human myeloidderived suppressor cells. J. Clin. Invest. 120, 457-471. doi: 10.1172/JCI40483

Chodobski, A., Zink, B. J., and Szmydynger-Chodobska, J. (2011). Blood-brain barrier pathophysiology in traumatic brain injury. Transl. Stroke Res. 2, 492516. doi: 10.1007/s12975-011-0125-x

Clarkson, B. D. S., Ling, C., Shi, Y., Harris, M. G., Rayasam, A., Sun, D., et al. (2014). T cell-derived interleukin (IL)-21 promotes brain injury following stroke in mice. J. Exp. Med. 211, 595-604. doi: 10.1084/jem.20131377

Clayton, A., Turkes, A., Navabi, H., Mason, M. D., and Tabi, Z. (2005). Induction of heat shock proteins in B-cell exosomes. J. Cell Sci. 118, 3631-3638. doi: $10.1242 /$ jcs.02494

Coles, J. P. (2004). Regional ischemia after head injury. Curr. Opin. Crit. Care 10, 120-125. doi: 10.1097/00075198-200404000-00008

Concannon, C. G., Gorman, A. M., and Samali, A. (2003). On the role of Hsp27 in regulating apoptosis. Apoptosis 8, 61-70. doi: 10.1023/A:1021601103096

Costantini, E., D'Angelo, C., and Reale, M. (2018). The role of immunosenescence in neurodegenerative diseases. Mediators Inflamm. 2018, 1-12. doi: $10.1155 / 2018 / 6039171$

Cox, D., Selig, E., Griffin, M. D. W., Carver, J. A., and Ecroyd, H. (2016). Small heat-shock proteins prevent $\alpha$-synuclein aggregation via transient interactions and their efficacy is affected by the rate of aggregation. J. Biol. Chem. 291, 22618-22629. doi: 10.1074/jbc.M116.739250

Crippa, V., D’Agostino, V. G., Cristofani, R., Rusmini, P., Cicardi, M. E., Messi, E., et al. (2016). Transcriptional induction of the heat shock protein B8 mediates the clearance of misfolded proteins responsible for motor neuron diseases. Sci. Rep. 6, 22827. doi: 10.1038/srep22827

Crippa, V., Sau, D., Rusmini, P., Boncoraglio, A., Onesto, E., Bolzoni, E., et al. (2010). The small heat shock protein B8 (HspB8) promotes autophagic removal of misfolded proteins involved in amyotrophic lateral sclerosis (ALS). Hum. Mol. Genet. 19, 3440-3456. doi: 10.1093/hmg/ddq257

Cristofani, R., Crippa, V., Vezzoli, G., Rusmini, P., Galbiati, M., Cicardi, M. E., et al. (2018). The small heat shock protein B8 (HSPB8) efficiently removes aggregating species of dipeptides produced in C9ORF72-related neurodegenerative diseases. Cell Stress Chaperones 23, 1-12. doi: 10.1007/s12192-017-0806-9

Crum, T., Gleixner, A., Posimo, J., Mason, D., Broeren, M., Heinemann, S. D., et al. (2015). Heat shock protein responses to aging and proteotoxicity in the olfactory bulb. J. Neurochem. 133 (6), 780-794. doi: 10.1111/jnc.13041

Csont, T., Balogh, G., Csonka, C., Boros, I., Horváth, I., Vigh, L., et al. (2002). Hyperlipidemia induced by high cholesterol diet inhibits heat shock response in rat hearts. Biochem. Biophys. Res. Commun. 290, 1535-1538. doi: 10.1006/ bbrc.2002.6377

Davalos, D., Grutzendler, J., Yang, G., Kim, J. V., Zuo, Y., Jung, S., et al. (2005). ATP mediates rapid microglial response to local brain injury in vivo. Nat. Neurosci. 8, 752-758. doi: $10.1038 / \mathrm{nn} 1472$

De Maio, A., and Vazquez, D. (2013). Extracellular heat shock proteins. Shock 40, 239-246. doi: 10.1097/SHK.0b013e3182a185ab

del Zoppo, G. J., Frankowski, H., Gu, Y.-H., Osada, T., Kanazawa, M., Milner, R., et al. (2012). Microglial cell activation is a source of metalloproteinase generation 
during hemorrhagic transformation. J. Cereb. Blood Flow Metab. 32, 919-932. doi: $10.1038 /$ jcbfm.2012.11

Dimitrijevic, O. B., Stamatovic, S. M., Keep, R. F., and Andjelkovic, A. V. (2007). Absence of the chemokine receptor CCR2 protects against cerebral ischemia/reperfusion injury in mice. Stroke 38, 1345-1353. doi: 10.1161/01. STR.0000259709.16654.8f

Dohi, E., Tanaka, S., Seki, T., Miyagi, T., Hide, I., Takahashi, T., et al. (2012). Hypoxic stress activates chaperone-mediated autophagy and modulates neuronal cell survival. Neurochem. Int. 60, 431-442. doi: 10.1016/j.neuint.2012.01.020

Dominik, P. K., and Kossiakoff, A. A. (2015). Phage display selections for affinity reagents to membrane proteins in nanodiscs. Methods Enzymol. 557, 219-245. doi: 10.1016/bs.mie.2014.12.032

Dutta, S. K., Girotra, M., Singla, M., Dutta, A., Otis Stephen, F., Nair, P. P., et al. (2012). Serum HSP70. Pancreas 41, 530-534. doi: 10.1097/MPA.0b013e3182374ace

Edgar, J. R. (2016). Q\&A: what are exosomes, exactly? BMC Biol. 14, 46. doi: 10.1186/s12915-016-0268-z

Ekimova, I. V., Nitsinskaya, L. E., Romanova, I. V., Pastukhov, Y. F., Margulis, B. A., and Guzhova, I. V. (2010). Exogenous protein Hsp70/Hsc70 can penetrate into brain structures and attenuate the severity of chemically-induced seizures. J. Neurochem. 115, 1035-1044. doi: 10.1111/j.1471-4159.2010.06989.x

El Khoury, J., Toft, M., Hickman, S. E., Means, T. K., Terada, K., Geula, C., et al. (2007). Ccr2 deficiency impairs microglial accumulation and accelerates progression of Alzheimer-like disease. Nat. Med. 13, 432-438. doi: 10.1038/nm1555

Elahy, M., Jackaman, C., Mamo, J., Lam, V., Dhaliwal, S. S., Giles, C., et al. (2015). Blood-brain barrier dysfunction developed during normal aging is associated with inflammation and loss of tight junctions but not with leukocyte recruitment. Immun. Ageing 12, 2. doi: 10.1186/s12979-015-0029-9

Fanelli, M. A., Cuello Carrión, F. D., Dekker, J., Schoemaker, J., and Ciocca, D. R. (1998). Serological detection of heat shock protein hsp27 in normal and breast cancer patients. Cancer Epidemiol. Biomarkers Prev. 7, 791-795.

Felger, J. C., Abe, T., Kaunzner, U. W., Gottfried-Blackmore, A., Gal-Toth, J., McEwen, B. S., et al. (2010). Brain dendritic cells in ischemic stroke: time course, activation state, and origin. Brain Behav. Immun. 24, 724-737. doi: 10.1016/j.bbi.2009.11.002

Feng, J.-T., Liu, Y.-K., Song, H.-Y., Dai, Z., Qin, L.-X., Almofti, M. R., et al. (2005). Heat-shock protein 27: a potential biomarker for hepatocellular carcinoma identified by serum proteome analysis. Proteomics 5, 4581-4588. doi: 10.1002/ pmic.200401309

Ferat-Osorio, E., Sánchez-Anaya, A., Gutiérrez-Mendoza, M., Boscó-Gárate, I., Wong-Baeza, I., Pastelin-Palacios, R., et al. (2014). Heat shock protein 70 down-regulates the production of toll-like receptor-induced pro-inflammatory cytokines by a heat shock factor-1/constitutive heat shock element-binding factor-dependent mechanism. J. Inflamm. 11, 19. doi: 10.1186/1476-9255-11-19

Fernandez-Funez, P., Sanchez-Garcia, J., de Mena, L., Zhang, Y., Levites, Y., Khare, S., et al. (2016). Holdase activity of secreted Hsp70 masks amyloid- $\beta 42$ neurotoxicity in Drosophila. Proc. Natl. Acad. Sci. 113, E5212-E5221. doi: $10.1073 /$ pnas. 1608045113

Feuerstein, G. Z., Liu, T., and Barone, F. C. (1994). Cytokines, inflammation, and brain injury: role of tumor necrosis factor-alpha. Cerebrovasc. Brain Metab. Rev. 6, 341-360.

Fiala, M., Lin, J., Ringman, J., Kermani-Arab, V., Tsao, G., Patel, A., et al. (2005). Ineffective phagocytosis of amyloid-beta by macrophages of Alzheimer's disease patients. J. Alzheimers Dis. 7, 221-232; discussion 255-262. doi: 10.3233/JAD-2005-7304

Floden, A. M., and Combs, C. K. (2011). Microglia demonstrate age-dependent interaction with amyloid- $\beta$ fibrils. J. Alzheimers Dis. 25, 279-293. doi: 10.3233/ JAD-2011-101014

Flygt, J., Ruscher, K., Norberg, A., Mir, A., Gram, H., Clausen, F., et al. (2018). Neutralization of interleukin- $1 \beta$ following diffuse traumatic brain injury in the mouse attenuates the loss of mature oligodendrocytes. J. Neurotrauma 35 , 2837-2849. doi: 10.1089/neu.2018.5660

Fog, C. K., Zago, P., Malini, E., Solanko, L. M., Peruzzo, P., Bornaes, C., et al. (2018). The heat shock protein amplifier arimoclomol improves refolding, maturation and lysosomal activity of glucocerebrosidase. EBioMedicine 38, 142-153. doi: 10.1016/j.ebiom.2018.11.037

Ford, A. L., Foulcher, E., Lemckert, F. A., and Sedgwick, J. D. (1996). Microglia induce CD4 T lymphocyte final effector function and death. J. Exp. Med. 184, 1737-1745. doi: 10.1084/jem.184.5.1737
Franciosi, S., Ryu, J. K., Shim, Y., Hill, A., Connolly, C., Hayden, M. R., et al. (2012). Age-dependent neurovascular abnormalities and altered microglial morphology in the YAC128 mouse model of Huntington disease. Neurobiol. Dis. 45, 438-449. doi: 10.1016/j.nbd.2011.09.003

Frik, J., Merl-Pham, J., Plesnila, N., Mattugini, N., Kjell, J., Kraska, J., et al. (2018). Cross-talk between monocyte invasion and astrocyte proliferation regulates scarring in brain injury. EMBO Rep. 19, e45294. doi: 10.15252/embr.201745294

Gammazza, A. M., Colangeli, R., Orban, G., Pierucci, M., Di Gennaro, G., Bello, M. L., et al. (2015). Hsp60 response in experimental and human temporal lobe epilepsy. Sci. Rep. 5, 9434. doi: 10.1038/srep09434

Gastpar, R., Gehrmann, M., Bausero, M. A., Asea, A., Gross, C., Schroeder, J. A., et al. (2005). Heat shock protein 70 surface-positive tumor exosomes stimulate migratory and cytolytic activity of natural killer cells. Cancer Res. 65, 52385247. doi: 10.1158/0008-5472.CAN-04-3804

Gehrmann, M., Specht, H. M., Bayer, C., Brandstetter, M., Chizzali, B., Duma, M., et al. (2014). Hsp70-a biomarker for tumor detection and monitoring of outcome of radiation therapy in patients with squamous cell carcinoma of the head and neck. Radiat. Oncol. 9, 131. doi: 10.1186/1748-717X-9-131

Gelders, G., Baekelandt, V., and Van der Perren, A. (2018). Linking neuroinflammation and neurodegeneration in Parkinson's disease. J. Immunol. Res. 2018, 1-12. doi: 10.1155/2018/4784268

Ghosh, S., Wu, M. D., Shaftel, S. S., Kyrkanides, S., LaFerla, F. M., Olschowka, J. A., et al. (2013). Sustained interleukin-1 $\beta$ overexpression exacerbates tau pathology despite reduced amyloid burden in an Alzheimer's mouse model. J. Neurosci. 33, 5053-5064. doi: 10.1523/JNEUROSCI.4361-12.2013

Gill, D., and Veltkamp, R. (2016). Dynamics of T cell responses after stroke. Curr. Opin. Pharmacol. 26, 26-32. doi: 10.1016/j.coph.2015.09.009

Girard, S., Brough, D., Lopez-Castejon, G., Giles, J., Rothwell, N. J., and Allan, S. M. (2013). Microglia and macrophages differentially modulate cell death after brain injury caused by oxygen-glucose deprivation in organotypic brain slices. Glia 61, 813-824. doi: 10.1002/glia.22478

Giuliano, J. S., Lahni, P. M., Wong, H. R., Wheeler, D. S., and Wheeler, D. S. (2011). Pediatric sepsis-part V: extracellular heat shock proteins: alarmins for the host immune system. Open Inflamm. J. 4, 49-60. doi: 10.2174/1875041901104010049

Glabinski, A. R., Tani, M., Aras, S., Stoler, M. H., Tuohy, V. K., and Ransohoff, R. M. (1995). Regulation and function of central nervous system chemokines. Int. J. Dev. Neurosci. 13, 153-165. doi: 10.1016/0736-5748(95)00017-B

Gleixner, A. M., Pulugulla, S. H., Pant, D. B., Posimo, J. M., Crum, T. S., and Leak, R. K. (2014). Impact of aging on heat shock protein expression in the substantia nigra and striatum of the female rat. Cell Tissue Res. 357, 43-54. doi: 10.1007/s00441-014-1852-6

Gliem, M., Schwaninger, M., and Jander, S. (2016). Protective features of peripheral monocytes/macrophages in stroke. Biochim. Biophys. Acta 1862, 329-338. doi: 10.1016/j.bbadis.2015.11.004

Goldgaber, D., Harris, H. W., Hla, T., Maciag, T., Donnelly, R. J., Jacobsen, J. S., et al. (1989). Interleukin 1 regulates synthesis of amyloid beta-protein precursor mRNA in human endothelial cells. Proc. Natl. Acad. Sci. U. S. A. 86, 7606-7610. doi: $10.1073 /$ pnas.86.19.7606

Gomez-Arboledas, A., Davila, J. C., Sanchez-Mejias, E., Navarro, V., Nuñez Diaz, C., Sanchez-Varo, R., et al. (2018). Phagocytic clearance of presynaptic dystrophies by reactive astrocytes in Alzheimer's disease. Glia 66, 637-653. doi: 10.1002/ glia. 23270

Gruden, G., Barutta, F., Catto, I., Bosco, G., Caprioli, M. G., Pinach, S., et al. (2013). Serum levels of heat shock protein 27 in patients with acute ischemic stroke. Cell Stress Chaperones 18, 531-533. doi: 10.1007/s12192-013-0403-5

Guillot-Sestier, M.-V., Doty, K. R., Gate, D., Rodriguez, J., Leung, B. P., Rezai Zadeh, K., et al. (2015). Illo deficiency rebalances innate immunity to mitigate Alzheimer-like pathology. Neuron 85, 534-548. doi: 10.1016/j. neuron.2014.12.068

Guo, K., Kang, N. X., Li, Y., Sun, L., Gan, L., Cui, F. J., et al. (2009). Regulation of HSP27 on NF-KB pathway activation may be involved in metastatic hepatocellular carcinoma cells apoptosis. BMC Cancer 9, 100. doi: $10.1186 / 1471-2407-9-100$

Gupta, A., and Pulliam, L. (2014). Exosomes as mediators of neuroinflammation. J. Neuroinflammation 11, 68. doi: 10.1186/1742-2094-11-68

Gupta, S., and Knowlton, A. A. (2007). HSP60 trafficking in adult cardiac myocytes: role of the exosomal pathway. Am. J. Physiol. Circ. Physiol. 292, H3052-H3056. doi: 10.1152/ajpheart.01355.2006 
Gupte, A. A., Morris, J. K., Zhang, H., Bomhoff, G. L., Geiger, P. C., and Stanford, J. A. (2010). Age-related changes in HSP25 expression in basal ganglia and cortex of F344/BN rats. Neurosci. Lett. 472, 90-93. doi: 10.1016/j. neulet.2010.01.049

Guzhova, I., Kislyakova, K., Moskaliova, O., Fridlanskaya, I., Tytell, M., Cheetham, M., et al. (2001). In vitro studies show that Hsp70 can be released by glia and that exogenous Hsp70 can enhance neuronal stress tolerance. Brain Res. 914, 66-73. doi: 10.1016/S0006-8993(01)02774-3

Halle, A., Hornung, V., Petzold, G. C., Stewart, C. R., Monks, B. G., Reinheckel, T., et al. (2008). The NALP3 inflammasome is involved in the innate immune response to amyloid-beta. Nat. Immunol. 9, 857-865. doi: 10.1038/ni.1636

He, P., Zhong, Z., Lindholm, K., Berning, L., Lee, W., Lemere, C., et al. (2007). Deletion of tumor necrosis factor death receptor inhibits amyloid beta generation and prevents learning and memory deficits in Alzheimer's mice. J. Cell Biol. 178, 829-841. doi: 10.1083/jcb.200705042

Hennessy, F., Nicoll, W. S., Zimmermann, R., Cheetham, M. E., and Blatch, G. L. (2005). Not all J domains are created equal: implications for the specificity of Hsp40-Hsp70 interactions. Protein Sci. 14, 1697-1709. doi: 10.1110/ps.051406805

Heydari, A. R., You, S., Takahashi, R., Gutsmann-Conrad, A., Sarge, K. D., and Richardson, A. (2000). Age-related alterations in the activation of heat shock transcription factor 1 in rat hepatocytes. Exp. Cell Res. 256, 83-93. doi: 10.1006/ excr.2000.4808

Hickman, S. E., Allison, E. K., and El Khoury, J. (2008). Microglial dysfunction and defective beta-amyloid clearance pathways in aging Alzheimer's disease mice. J. Neurosci. 28, 8354-8360. doi: 10.1523/JNEUROSCI.0616-08.2008

Hightower, L. E., and Guidon, P. T. (1989). Selective release from cultured mammalian cells of heat-shock (stress) proteins that resemble glia-axon transfer proteins. J. Cell. Physiol. 138, 257-266. doi: 10.1002/jcp.1041380206

Hirakawa, T., Rokutan, K., Nikawa, T., and Kishi, K. (1996). Geranylgeranylacetone induces heat shock proteins in cultured guinea pig gastric mucosal cells and rat gastric mucosa. Gastroenterology 111, 345-357. doi: 10.1053/gast.1996.v111. pm8690199

Hollingworth, P., Harold, D., Sims, R., Gerrish, A., Lambert, J.-C., Carrasquillo, M. M., et al. (2011). Common variants at ABCA7, MS4A6A/ MS4A4E, EPHA1, CD33 and CD2AP are associated with Alzheimer's disease. Nat. Genet. 43, 429-435. doi: 10.1038/ng.803

Hong, H. S., Hwang, E. M., Sim, H. J., Cho, H.-J., Boo, J. H., Oh, S. S., et al. (2003). Interferon gamma stimulates beta-secretase expression and sAPPbeta production in astrocytes. Biochem. Biophys. Res. Commun. 307, 922-927. doi: 10.1016/S0006-291X(03)01270-1

Hooper, P. L., Durham, H. D., Török, Z., Hooper, P. L., Crul, T., and Vígh, L. (2016). The central role of heat shock factor 1 in synaptic fidelity and memory consolidation. Cell Stress Chaperones 21, 745-753. doi: 10.1007/ s12192-016-0709-1

Horváth, I., Multhoff, G., Sonnleitner, A., and Vígh, L. (2008). Membraneassociated stress proteins: more than simply chaperones. Biochim. Biophys. Acta Biomembr. 1778, 1653-1664. doi: 10.1016/j.bbamem.2008.02.012

Hoshino, T., Murao, N., Namba, T., Takehara, M., Adachi, H., Katsuno, M., et al. (2011). Suppression of Alzheimer's disease-related phenotypes by expression of heat shock protein 70 in mice. J. Neurosci. 31, 5225-5234. doi: 10.1523/ JNEUROSCI.5478-10.2011

Hosomi, N., Ban, C. R., Naya, T., Takahashi, T., Guo, P., Song, X. R., et al. (2005). Tumor necrosis factor-alpha neutralization reduced cerebral edema through inhibition of matrix metalloproteinase production after transient focal cerebral ischemia. J. Cereb. Blood Flow Metab. 25, 959-967. doi: 10.1038/ sj.jcbfm.9600086

Houenou, L. J., Li, L., Lei, M., Kent, C. R., and Tytell, M. (1996). Exogenous heat shock cognate protein Hsc 70 prevents axotomy-induced death of spinal sensory neurons. Cell Stress Chaperones 1, 161-166. doi: 10.1379/1466-1268(1996)001<0161:EHSCPH>2.3.CO;2

Hu, X., Li, P., Guo, Y., Wang, H., Leak, R. K., Chen, S., et al. (2012). Microglia/ macrophage polarization dynamics reveal novel mechanism of injury expansion after focal cerebral ischemia. Stroke 43, 3063-3070. doi: 10.1161/ STROKEAHA.112.659656

Huang, Q., Ye, J., Huang, Q., Chen, W., Wang, L., Lin, W., et al. (2010). Heat shock protein 27 is over-expressed in tumor tissues and increased in sera of patients with gastric adenocarcinoma. Clin. Chem. Lab. Med. 48, 263-269. doi: 10.1515/ CCLM.2010.043
Hunter-Lavin, C., Davies, E. L., Bacelar, M. M. F. V. G., Marshall, M. J., Andrew, S. M., and Williams, J. H. H. (2004). Hsp70 release from peripheral blood mononuclear cells. Biochem. Biophys. Res. Commun. 324, 511-517. doi: 10.1016/j.bbrc.2004.09.075

Inouye, S., Fujimoto, M., Nakamura, T., Takaki, E., Hayashida, N., Hai, T., et al. (2007). Heat Shock transcription factor 1 opens chromatin structure of interleukin-6 promoter to facilitate binding of an activator or a repressor. J. Biol. Chem. 282, 33210-33217. doi: 10.1074/jbc.M704471200

Ito, M., Komai, K., Mise-Omata, S., Iizuka-Koga, M., Noguchi, Y., Kondo, T., et al. (2019). Brain regulatory $\mathrm{T}$ cells suppress astrogliosis and potentiate neurological recovery. Nature 565, 246-250. doi: 10.1038/s41586-018-0824-5

Jack, C. S., Arbour, N., Manusow, J., Montgrain, V., Blain, M., McCrea, E., et al. (2005). TLR signaling tailors innate immune responses in human microglia and astrocytes. J. Immunol. 175, 4320-4330. doi: 10.4049/jimmunol.175. 7.4320

Jin, C., Cleveland, J. C., Ao, L., Li, J., Zeng, Q., Fullerton, D. A., et al. (2014). Human myocardium releases heat shock protein 27 (HSP27) after global ischemia: the proinflammatory effect of extracellular HSP27 through toll-like receptor (TLR)-2 and TLR4. Mol. Med. 20, 280-289. doi: 10.2119/molmed. 2014.00058

Jin, W.-N., Shi, S. X.-Y., Li, Z., Li, M., Wood, K., Gonzales, R. J., et al. (2017). Depletion of microglia exacerbates postischemic inflammation and brain injury. J. Cereb. Blood Flow Metab. 37, 2224-2236. doi: 10.1177/0271678X17694185

Jonsson, T., Stefansson, H., Steinberg, S., Jonsdottir, I., Jonsson, P. V., Snaedal, J., et al. (2013). Variant of TREM2 associated with the risk of Alzheimer's disease. N. Engl. J. Med. 368, 107-116. doi: 10.1056/NEJMoa1211103

Kakimura, J. I., Kitamura, Y., Takata, K., Umeki, M., Suzuki, S., Shibagaki, K., et al. (2002). Microglia activation and amyloid- $\beta$ clearance induced by exogenous heat shock proteins. FASEB. J. 16, 601-603. doi: 10.1096/fj.01-0530fje

Kalmar, B., Burnstock, G., Vrbová, G., Urbanics, R., Csermely, P., and Greensmith, L. (2002). Upregulation of heat shock proteins rescues motoneurones from axotomy-induced cell death in neonatal rats. Exp. Neurol. 176, 87-97. doi: 10.1006/exnr.2002.7945

Kalmar, B., Greensmith, L., Malcangio, M., McMahon, S., Csermely, P., and Burnstock, G. (2003). The effect of treatment with BRX-220, a co-inducer of heat shock proteins, on sensory fibers of the rat following peripheral nerve injury. Exp. Neurol. 184, 636-647. doi: 10.1016/S0014-4886(03)00343-1

Kammanadiminti, S. J., and Chadee, K. (2006). Suppression of NF- $\kappa$ B activation by Entamoeba histolytica in intestinal epithelial cells is mediated by heat shock protein 27. J. Biol. Chem. 281, 26112-26120. doi: 10.1074/jbc.M601988200

Kampinga, H. H. (2006). Chaperones in preventing protein denaturation in living cells and protecting against cellular stress. Handb. Exp. Pharmacol. 172, 1-42. doi: 10.1007/3-540-29717-0_1

Kampinga, H. H., and Craig, E. A. (2010). The HSP70 chaperone machinery: J proteins as drivers of functional specificity. Nat. Rev. Mol. Cell Biol. 11, 579592. doi: $10.1038 / \mathrm{nrm} 2941$

Kampinga, H. H., Hageman, J., Vos, M. J., Kubota, H., Tanguay, R. M., Bruford, E. A., et al. (2009). Guidelines for the nomenclature of the human heat shock proteins. Cell Stress Chaperones 14, 105-111. doi: 10.1007/s12192-008-0068-7

Kasza, Á., Hunya, Á., Frank, Z., Fülöp, F., Török, Z., Balogh, G., et al. (2016). Dihydropyridine Derivatives modulate heat shock responses and have a neuroprotective effect in a transgenic mouse model of Alzheimer's disease. J. Alzheimers Dis. 53, 557-571. doi: 10.3233/JAD-150860

Kaushal, V., and Schlichter, L. C. (2008). Mechanisms of microglia-mediated neurotoxicity in a new model of the stroke penumbra. J. Neurosci. 28, 22212230. doi: 10.1523/JNEUROSCI.5643-07.2008

Kawabori, M., and Yenari, M. A. (2015). The role of the microglia in acute CNS injury. Metab. Brain Dis. 30, 381-392. doi: 10.1007/s11011-014-9531-6

Kelty, J. D., Noseworthy, P. A., Feder, M. E., Robertson, R. M., and Ramirez, J.-M. (2002). Thermal preconditioning and heat-shock protein 72 preserve synaptic transmission during thermal stress. J. Neurosci. 22, RC193. doi: 10.1523/ JNEUROSCI.22-01-j0004.2002

Kern, A., Ackermann, B., Clement, A. M., Duerk, H., and Behl, C. (2010). HSF1controlled and age-associated chaperone capacity in neurons and muscle cells of C. elegans. PLoS One 5, e8568. doi: 10.1371/journal.pone.0008568

Kern, J., Untergasser, G., Zenzmaier, C., Sarg, B., Gastl, G., Gunsilius, E., et al. (2009). GRP-78 secreted by tumor cells blocks the antiangiogenic activity of bortezomib. Blood 114, 3960-3967. doi: 10.1182/blood-2009-03-209668 
Khandelwal, P. J., Herman, A. M., and Moussa, C. E.-H. (2011). Inflammation in the early stages of neurodegenerative pathology. J. Neuroimmunol. 238, 1-11. doi: 10.1016/j.jneuroim.2011.07.002

Kiaei, M., Kipiani, K., Petri, S., Chen, J., Calingasan, N. Y., and Beal, M. F. (2005). Celastrol blocks neuronal cell death and extends life in transgenic mouse model of amyotrophic lateral sclerosis. Neurodegener. Dis. 2, 246-254. doi: 10.1159/000090364

Kieran, D., Kalmar, B., Dick, J., Riddoch-Contreras, J., Burnstock, G., and Greensmith, L. (2004). Treatment with arimoclomol, a coinducer of heat shock proteins, delays disease progression in ALS mice. Nat. Med. 10, 402-405. doi: $10.1038 / \mathrm{nm} 1021$

Kim, J. Y., and Yenari, M. A. (2013). The immune modulating properties of the heat shock proteins after brain injury. Anat. Cell Biol. 46, 1-7. doi: 10.5115/ acb.2013.46.1.1

Kim, G., Meriin, A. B., Gabai, V. L., Christians, E., Benjamin, I., Wilson, A., et al. (2012). The heat shock transcription factor Hsf1 is downregulated in DNA damage-associated senescence, contributing to the maintenance of senescence phenotype. Aging Cell 11, 617-627. doi: 10.1111/j.1474-9726.2012.00827.x

Kim, J. Y., Kim, N., Zheng, Z., Lee, J. E., and Yenari, M. A. (2016). 70-kDa heat shock protein downregulates dynamin in experimental stroke: a new therapeutic target? Stroke 47, 2103-2111. doi: 10.1161/STROKEAHA.116.012763

Kim, N., Kim, J. Y., and Yenari, M. A. (2015). Pharmacological induction of the $70-\mathrm{kDa}$ heat shock protein protects against brain injury. Neuroscience 284, 912-919. doi: 10.1016/j.neuroscience.2014.11.010

Kitazawa, M., Oddo, S., Yamasaki, T. R., Green, K. N., and LaFerla, F. M. (2005). Lipopolysaccharide-induced inflammation exacerbates tau pathology by a cyclindependent kinase 5-mediated pathway in a transgenic model of Alzheimer's disease. J. Neurosci. 25, 8843-8853. doi: 10.1523/JNEUROSCI.2868-05.2005

Knoblach, S. M., and Faden, A. I. (1998). Interleukin-10 improves outcome and alters proinflammatory cytokine expression after experimental traumatic brain injury. Exp. Neurol. 153, 143-151. doi: 10.1006/exnr.1998.6877

Koll, H., Guiard, B., Rassow, J., Ostermann, J., Horwich, A. L., Neupert, W., et al. (1992). Antifolding activity of hsp60 couples protein import into the mitochondrial matrix with export to the intermembrane space. Cell 68, 11631175. doi: 10.1016/0092-8674(92)90086-R

Krabbe, G., Halle, A., Matyash, V., Rinnenthal, J. L., Eom, G. D., Bernhardt, U., et al. (2013). Functional impairment of microglia coincides with beta-amyloid deposition in mice with Alzheimer-like pathology. PLoS One 8, e60921. doi: 10.1371/journal.pone.0060921

Kraft, A. D., Kaltenbach, L. S., Lo, D. C., and Harry, G. J. (2012). Activated microglia proliferate at neurites of mutant huntingtin-expressing neurons. Neurobiol. Aging 33, 621.e17-621.e33. doi: 10.1016/j.neurobiolaging.2011.02.015

Kuai, R., Ochyl, L. J., Bahjat, K. S., Schwendeman, A., and Moon, J. J. (2017). Designer vaccine nanodiscs for personalized cancer immunotherapy. Nat. Mater. 16, 489-496. doi: 10.1038/nmat4822

Kültz, D. (2005). Molecular and evolutionary basis of the cellular stress response. Annu. Rev. Physiol.67,225-257. doi: 10.1146/annurev.physiol.67.040403.103635

Kürthy, M., Mogyorósi, T., Nagy, K., Kukorelli, T., Jednákovits, A., Tálosi, L., et al. (2002). Effect of BRX-220 against peripheral neuropathy and insulin resistance in diabetic rat models. Ann. N. Y. Acad. Sci. 967, 482-489. doi: 10.1111/j.17496632.2002.tb04306.x

Lambert, J.-C., Heath, S., Even, G., Campion, D., Sleegers, K., Hiltunen, M., et al. (2009). Genome-wide association study identifies variants at CLU and CR1 associated with Alzheimer's disease. Nat. Genet. 41, 1094-1099. doi: 10.1038/ng.439

Lanneau, D., Brunet, M., Frisan, E., Solary, E., Fontenay, M., and Garrido, C. (2008). Heat shock proteins: essential proteins for apoptosis regulation. J. Cell. Mol. Med. 12, 743-761. doi: 10.1111/j.1582-4934.2008.00273.x

Laurent, C., Buée, L., and Blum, D. (2018). Tau and neuroinflammation: what impact for Alzheimer's disease and tauopathies? Biomed. J. 41, 21-33. doi: 10.1016/j.bj.2018.01.003

Le, W., Wu, J., and Tang, Y. (2016). Protective microglia and their regulation in Parkinson's disease. Front Mol. Neurosci. 9, 89. doi: 10.3389/fnmol.2016.00089

Lee, C.-T., and Repasky, E. A. (2012). Opposing roles for heat and heat shock proteins in macrophage functions during inflammation: a function of cell activation state? Front. Immunol. 3, 140. doi: 10.3389/fimmu.2012.00140

Lee, H.-J., Suk, J.-E., Patrick, C., Bae, E.-J., Cho, J.-H., Rho, S., et al. (2010). Direct transfer of alpha-synuclein from neuron to astroglia causes inflammatory responses in synucleinopathies. J. Biol. Chem. 285, 9262-9272. doi: 10.1074/ jbc.M109.081125

Lee, J.-M., Grabb, M. C., Zipfel, G. J., and Choi, D. W. (2000). Brain tissue responses to ischemia. J. Clin. Invest. 106, 723-731. doi: 10.1172/JCI11003

Lee, Y.-J., Lee, H.-J., Choi, S., Jin, Y. B., An, H. J., Kang, J.-H., et al. (2012a). Soluble HSPB1 regulates VEGF-mediated angiogenesis through their direct interaction. Angiogenesis 15, 229-242. doi: 10.1007/s10456-012-9255-3

Lee, T. H., Park, J. H., Kim, J.-D., Lee, J.-C., Kim, I. H., Yim, Y., et al. (2012b). Protective effects of a novel synthetic alpha-lipoic acid-decursinol hybrid compound in experimentally induced transient cerebral ischemia. Cell. Mol. Neurobiol. 32, 1209-1221. doi: 10.1007/s10571-012-9861-Z

Lehnardt, S., Schott, E., Trimbuch, T., Laubisch, D., Krueger, C., Wulczyn, G., et al. (2008). A vicious cycle involving release of heat shock protein 60 from injured cells and activation of toll-like receptor 4 mediates neurodegeneration in the CNS. J. Neurosci. 28, 2320-2331. doi: 10.1523/JNEUROSCI.4760-07.2008

Lehr, S., Hartwig, S., Lamers, D., Famulla, S., Müller, S., Hanisch, F.-G., et al. (2012). Identification and validation of novel adipokines released from primary human adipocytes. Mol. Cell. Proteomics 11, 1-13. doi: 10.1074/mcp.M111.010504

Liao, W.-C., Wu, M.-S., Wang, H.-P., Tien, Y.-W., and Lin, J.-T. (2009). Serum heat shock protein 27 is increased in chronic pancreatitis and pancreatic carcinoma. Pancreas 38, 422-426. doi: 10.1097/MPA.0b013e318198281d

Liesz, A., Bauer, A., Hoheisel, J. D., and Veltkamp, R. (2014). Intracerebral interleukin-10 injection modulates post-ischemic neuroinflammation: an experimental microarray study. Neurosci. Lett. 579, 18-23. doi: 10.1016/j. neulet.2014.07.003

Liesz, A., Suri-Payer, E., Veltkamp, C., Doerr, H., Sommer, C., Rivest, S., et al. (2009). Regulatory T cells are key cerebroprotective immunomodulators in acute experimental stroke. Nat. Med. 15, 192-199. doi: 10.1038/nm.1927

Lin, L., Wang, X., and Yu, Z. (2016). Ischemia-reperfusion injury in the brain: mechanisms and potential therapeutic strategies. Biochem. Pharmacol. Open Access 5, 213. doi: 10.4172/2167-0501.1000213

Lindenau, J. D., Altmann, V., Schumacher-Schuh, A. F., Rieder, C. R., and Hutz, M. H. (2017). Tumor necrosis factor alpha polymorphisms are associated with Parkinson's disease age at onset. Neurosci. Lett. 658, 133-136. doi: 10.1016/j.neulet.2017.08.049

Lindquist, S. (1986). The heat-shock response. Annu. Rev. Biochem. 55, 1151-1191. doi: 10.1146/annurev.bi.55.070186.005443

Liu, L., An, D., Xu, J., Shao, B., Li, X., and Shi, J. (2018b). Ac2-26 induces $i k k \beta$ degradation through chaperone-mediated autophagy via HSPB1 in NCM-treated microglia. Front. Mol. Neurosci. 11, 76. doi: 10.3389/ fnmol.2018.00076

Liu, Y.-W., Li, S., and Dai, S.-S. (2018a). Neutrophils in traumatic brain injury (TBI): friend or foe? J. Neuroinflammation 15, 146. doi: 10.1186/s12974-018-1173-X

Llovera, G., Benakis, C., Enzmann, G., Cai, R., Arzberger, T., Ghasemigharagoz, A., et al. (2017). The choroid plexus is a key cerebral invasion route for $\mathrm{T}$ cells after stroke. Acta Neuropathol. 134, 851-868. doi: 10.1007/s00401-017-1758-y

Lou, N., Takano, T., Pei, Y., Xavier, A. L., Goldman, S. A., and Nedergaard, M. (2016). Purinergic receptor P2RY12-dependent microglial closure of the injured blood-brain barrier. Proc. Natl. Acad. Sci. U. S. A. 113, 1074-1079. doi: 10.1073/pnas.1520398113

Lu, K.-T., Wang, Y.-W., Yang, J.-T., Yang, Y.-L., and Chen, H.-I. (2005). Effect of interleukin-1 on traumatic brain injury-induced damage to hippocampal neurons. J. Neurotrauma 22, 885-895. doi: 10.1089/neu.2005.22.885

Luo, X.-G., Ding, J.-Q., and Chen, S.-D. (2010). Microglia in the aging brain: relevance to neurodegeneration. Mol. Neurodegener. 5, 12. doi: 10.1186/1750-1326-5-12

Maity, T. K., Henry, M. M., Tulapurkar, M. E., Shah, N. G., Hasday, J. D., and Singh, I. S. (2011). Distinct, gene-specific effect of heat shock on heat shock factor-1 recruitment and gene expression of CXC chemokine genes. Cytokine 54, 61-67. doi: 10.1016/j.cyto.2010.12.017

Malik, M., Parikh, I., Vasquez, J. B., Smith, C., Tai, L., Bu, G., et al. (2015). Genetics ignite focus on microglial inflammation in Alzheimer's disease. Mol. Neurodegener. 10, 52. doi: 10.1186/s13024-015-0048-1

Malo, C. S., Huggins, M. A., Goddery, E. N., Tolcher, H. M. A., Renner, D. N., Jin, F., et al. (2018). Non-equivalent antigen presenting capabilities of dendritic cells and macrophages in generating brain-infiltrating CD8 $+\mathrm{T}$ cell responses. Nat. Commun. 9, 633. doi: 10.1038/s41467-018-03037-x 
Mambula, S. S., and Calderwood, S. K. (2006). Heat induced release of Hsp70 from prostate carcinoma cells involves both active secretion and passive release from necrotic cells. Int. J. Hyperth. 22, 575-585. doi: 10.1080/02656730600976042

Masilamoni, J. G., Jesudason, E. P., Baben, B., Jebaraj, C. E., Dhandayuthapani, S., and Jayakumar, R. (2006). Molecular chaperone $\alpha$-crystallin prevents detrimental effects of neuroinflammation. Biochim. Biophys. Acta Mol. Basis Dis. 1762, $284-$ 293. doi: 10.1016/j.bbadis.2005.11.007

Mayer, M. P., and Bukau, B. (2005). Hsp70 chaperones: cellular functions and molecular mechanism. Cell. Mol. Life Sci. 62, 670-684. doi: 10.1007/ s00018-004-4464-6

McCready, J., Sims, J. D., Chan, D., and Jay, D. G. (2010). Secretion of extracellular hsp90alpha via exosomes increases cancer cell motility: a role for plasminogen activation. BMC Cancer 10, 294. doi: 10.1186/1471-2407-10-294

Medeiros, R., and LaFerla, F. M. (2013). Astrocytes: conductors of the Alzheimer disease neuroinflammatory symphony. Exp. Neurol. 239, 133-138. doi: 10.1016/j.expneurol.2012.10.007

Melle, C., Ernst, G., Escher, N., Hartmann, D., Schimmel, B., Bleul, A., et al. (2007). Protein Profiling of Microdissected pancreas carcinoma and identification of HSP27 as a potential serum marker. Clin. Chem. 53, 629-635. doi: 10.1373/ clinchem.2006.079194

Miller, D. J., and Fort, P. E. (2018). Heat shock proteins regulatory role in neurodevelopment. Front. Neurosci. 12, 821. doi: 10.3389/fnins.2018.00821

Monsonego, A., Zota, V., Karni, A., Krieger, J. I., Bar-Or, A., Bitan, G., et al. (2003). Increased $\mathrm{T}$ cell reactivity to amyloid beta protein in older humans and patients with Alzheimer disease. J. Clin. Invest. 112, 415-422. doi: 10.1172/JCI18104

Montagne, A., Barnes, S. R., Sweeney, M. D., Halliday, M. R., Sagare, A. P., Zhao, Z., et al. (2015). Blood-brain barrier breakdown in the aging human hippocampus. Neuron 85, 296-302. doi: 10.1016/j.neuron.2014.12.032

Morimoto, R. I. (1998). Regulation of the heat shock transcriptional response: cross talk between a family of heat shock factors, molecular chaperones, and negative regulators. Genes Dev. 12, 3788-3796. doi: 10.1101/gad.12.24.3788

Morris, S. D., Cumming, D. V., Latchman, D. S., and Yellon, D. M. (1996). Specific induction of the $70-\mathrm{kD}$ heat stress proteins by the tyrosine kinase inhibitor herbimycin-A protects rat neonatal cardiomyocytes. a new pharmacological route to stress protein expression? J. Clin. Invest. 97, 706-712. doi: 10.1172/ JCI118468

Mosley, K., and Cuzner, M. L. (1996). Receptor-mediated phagocytosis of myelin by macrophages and microglia: effect of opsonization and receptor blocking agents. Neurochem. Res. 21, 481-487. doi: 10.1007/BF02527713

Moxon-Emre, I., and Schlichter, L. C. (2011). Neutrophil depletion reduces bloodbrain barrier breakdown, axon injury, and inflammation after intracerebral hemorrhage. J. Neuropathol. Exp. Neurol. 70, 218-235. doi: 10.1097/ NEN.0b013e31820d94a5

Murshid, A., Gong, J., and Calderwood, S. K. (2010). Heat shock protein 90 mediates efficient antigen cross presentation through the scavenger receptor expressed by endothelial cells-I. J. Immunol. 185, 2903-2917. doi: 10.4049/ jimmunol.0903635

Nafar, F., Williams, J. B., and Mearow, K. M. (2016). Astrocytes release HspB1 in response to amyloid- $\beta$ exposure in vitro. J. Alzheimers Dis. 49, 251-263. doi: 10.3233/JAD-150317

Naj, A. C., Jun, G., Beecham, G. W., Wang, L.-S., Vardarajan, B. N., Buros, J., et al. (2011). Common variants at MS4A4/MS4A6E, CD2AP, CD33 and EPHA1 are associated with late-onset Alzheimer's disease. Nat. Genet. 43, 436-441. doi: 10.1038/ng.801

Nakhjavani, M., Morteza, A., Khajeali, L., Esteghamati, A., Khalilzadeh, O., Asgarani, F., et al. (2010). Increased serum HSP70 levels are associated with the duration of diabetes. Cell Stress Chaperones 15, 959-964. doi: 10.1007/ s12192-010-0204-Z

Neueder, A., Gipson, T. A., Batterton, S., Lazell, H. J., Farshim, P. P., Paganetti, P., et al. (2017). HSF1-dependent and -independent regulation of the mammalian in vivo heat shock response and its impairment in Huntington's disease mouse models. Sci. Rep. 7, 12556. doi: 10.1038/s41598-017-12897-0

Newell, E. A., Todd, B. P., Mahoney, J., Pieper, A. A., Ferguson, P. J., and Bassuk, A. G. (2018). Combined blockade of interleukin-1 $\alpha$ and $-1 \beta$ signaling protects mice from cognitive dysfunction after traumatic brain injury. eNeuro 5, 1-15. doi: 10.1523/ENEURO.0385-17.2018

Nguyen, H. X., O’Barr, T. J., and Anderson, A. J. (2007). Polymorphonuclear leukocytes promote neurotoxicity through release of matrix metalloproteinases, reactive oxygen species, and TNF-alpha. J. Neurochem. 102, 900-912. doi: 10.1111/j.1471-4159.2007.04643.x

Ousman, S. S., Tomooka, B. H., van Noort, J. M., Wawrousek, E. F., O’Conner, K., Hafler, D. A., et al. (2007). Protective and therapeutic role for aB-crystallin in autoimmune demyelination. Nature 448, 474-479. doi: 10.1038/nature05935

Parfitt, D. A., Aguila, M., McCulley, C. H., Bevilacqua, D., Mendes, H. F., Athanasiou, D., et al. (2014). The heat-shock response co-inducer arimoclomol protects against retinal degeneration in rhodopsin retinitis pigmentosa. Cell Death Dis. 5, e1236-e1236. doi: 10.1038/cddis.2014.214

Patel, S. (2018). Danger-associated molecular patterns (DAMPs): the derivatives and triggers of inflammation. Curr. Allergy Asthma Rep. 18, 63. doi: 10.1007/ s11882-018-0817-3

Penke, B., Bogár, F., Crul, T., Sántha, M., Tóth, M. E., and Vígh, L. (2018). Heat shock proteins and autophagy pathways in neuroprotection: from molecular bases to pharmacological interventions. Int. J. Mol. Sci. 19, 324-340 doi: 10.3390/ ijms19010325

Péter, M., Balogh, G., Gombos, I., Liebisch, G., Horváth, I., Török, Z., et al. (2012). Nutritional lipid supply can control the heat shock response of B16 melanoma cells in culture. Mol. Membr. Biol. 29, 274-289. doi: 10.3109/09687688.2012. 680203

Phukan, J. (2010). Arimoclomol, a coinducer of heat shock proteins for the potential treatment of amyotrophic lateral sclerosis. IDrugs 13, 482-496.

Pido-Lopez, J., Whittall, T., Wang, Y., Bergmeier, L. A., Babaahmady, K., Singh, M., et al. (2007). Stimulation of cell surface CCR5 and CD40 molecules by their ligands or by HSP70 up-regulates APOBEC3G expression in CD4+ $\mathrm{T}$ cells and dendritic cells. J. Immunol. 178, 1671-1679. doi: 10.4049/ jimmunol.178.3.1671

Pihlaja, R., Koistinaho, J., Kauppinen, R., Sandholm, J., Tanila, H., and Koistinaho, M. (2011). Multiple cellular and molecular mechanisms are involved in human $A \beta$ clearance by transplanted adult astrocytes. Glia 59, 1643-1657. doi: 10.1002/ glia. 21212

Politis, M., Pavese, N., Tai, Y. F., Kiferle, L., Mason, S. L., Brooks, D. J., et al. (2011). Microglial activation in regions related to cognitive function predicts disease onset in Huntington's disease: a multimodal imaging study. Hum. Brain Mapp. 32, 258-270. doi: 10.1002/hbm.21008

Quintana, F. J., and Cohen, I. R. (2005). Heat shock proteins as endogenous adjuvants in sterile and septic inflammation. J. Immunol. 175, 2777-2782. doi: 10.4049/jimmunol.175.5.2777

Rayaprolu, S., Mullen, B., Baker, M., Lynch, T., Finger, E., Seeley, W. W., et al. (2013) TREM2 in neurodegeneration: evidence for association of the p.R47H variant with frontotemporal dementia and Parkinson's disease. Mol. Neurodegener. 8, 19. doi: 10.1186/1750-1326-8-19

Rayner, K., Chen, Y.-X., McNulty, M., Simard, T., Zhao, X., Wells, D. J., et al. (2008). Extracellular release of the atheroprotective heat shock protein 27 is mediated by estrogen and competitively inhibits acLDL binding to scavenger receptor-A. Circ. Res. 103, 133-141. doi: 10.1161/CIRCRESAHA.108.172155

Rayner, K., Sun, J., Chen, Y.-X., McNulty, M., Simard, T., Zhao, X., et al. (2009). Heat shock protein 27 protects against atherogenesis via an estrogendependent mechanism. Arterioscler. Thromb. Vasc. Biol. 29, 1751-1756. doi: 10.1161/ATVBAHA.109.193656

Reddy, V. S., Madala, S. K., Trinath, J., and Reddy, G. B. (2018). Extracellular small heat shock proteins: exosomal biogenesis and function. Cell Stress Chaperones 23, 441-454. doi: 10.1007/s12192-017-0856-Z

Richter, K., Haslbeck, M., and Buchner, J. (2010). The heat shock response: life on the verge of death. Mol. Cell 40, 253-266. doi: 10.1016/j.molcel.2010. 10.006

Ritzel, R. M., Patel, A. R., Grenier, J. M., Crapser, J., Verma, R., Jellison, E. R., et al. (2015). Functional differences between microglia and monocytes after ischemic stroke. J. Neuroinflammation 12, 106. doi: 10.1186/s12974-015-0329-1

Rosell, A., Cuadrado, E., Ortega-Aznar, A., Hernández-Guillamon, M., Lo, E. H., and Montaner, J. (2008). MMP-9-positive neutrophil infiltration is associated to blood-brain barrier breakdown and basal lamina type IV collagen degradation during hemorrhagic transformation after human ischemic stroke. Stroke 39, 1121-1126. doi: 10.1161/STROKEAHA.107.500868

Rosenberger, K., Dembny, P., Derkow, K., Engel, O., Krüger, C., Wolf, S. A., et al. (2015). Intrathecal heat shock protein 60 mediates neurodegeneration and demyelination in the CNS through a TLR4- and MyD88-dependent pathway. Mol. Neurodegener. 10, 5. doi: 10.1186/s13024-015-0003-1 
Roth, T. L., Nayak, D., Atanasijevic, T., Koretsky, A. P., Latour, L. L., and McGavern, D. B. (2014). Transcranial amelioration of inflammation and cell death after brain injury. Nature 505, 223-228. doi: 10.1038/nature12808

Rothwell, N. (2003). Interleukin-1 and neuronal injury: mechanisms, modification, and therapeutic potential. Brain Behav. Immun. 17, 152-157. doi: 10.1016/ S0889-1591(02)00098-3

Rouck, J. E., Krapf, J. E., Roy, J., Huff, H. C., and Das, A. (2017). Recent advances in nanodisc technology for membrane protein studies (2012-2017). FEBS Lett. 591, 2057-2088. doi: 10.1002/1873-3468.12706

Sairanen, T., Carpén, O., Karjalainen-Lindsberg, M. L., Paetau, A., Turpeinen, U., Kaste, M., et al. (2001). Evolution of cerebral tumor necrosis factor-alpha production during human ischemic stroke. Stroke 32, 1750-1758. doi: 10.1161/01.STR.32.8.1750

Saito, K., Dai, Y., and Ohtsuka, K. (2005). Enhanced expression of heat shock proteins in gradually dying cells and their release from necrotically dead cells. Exp. Cell Res. 310, 229-236. doi: 10.1016/j.yexcr.2005.07.014

Salari, S., Seibert, T., Chen, Y.-X., Hu, T., Shi, C., Zhao, X., et al. (2013). Extracellular HSP27 acts as a signaling molecule to activate NF- $\kappa B$ in macrophages. Cell Stress Chaperones 18, 53-63. doi: 10.1007/s12192-012-0356-0

Saresella, M., La Rosa, F., Piancone, F., Zoppis, M., Marventano, I., Calabrese, E., et al. (2016). The NLRP3 and NLRP1 inflammasomes are activated in Alzheimer's disease. Mol. Neurodegener. 11,23. doi: 10.1186/s13024-016-0088-1

Savage, J. C., Jay, T., Goduni, E., Quigley, C., Mariani, M. M., Malm, T., et al. (2015). Nuclear receptors license phagocytosis by Trem $2+$ myeloid cells in mouse models of Alzheimer's disease. J. Neurosci. 35, 6532-6543. doi: 10.1523/ JNEUROSCI.4586-14.2015

Scherbel, U., Raghupathi, R., Nakamura, M., Saatman, K. E., Trojanowski, J. Q., Neugebauer, E., et al. (1999). Differential acute and chronic responses of tumor necrosis factor-deficient mice to experimental brain injury. Proc. Natl. Acad. Sci. U.S.A. 96, 8721-8726. doi: 10.1073/pnas.96.15.8721

Schett, G., Steiner, C.-W., Xu, Q., Smolen, J. S., and Steiner, G. (2003). TNFa mediates susceptibility to heat-induced apoptosis by protein phosphatasemediated inhibition of the HSF1/hsp70 stress response. Cell Death Differ. 10, 1126-1136. doi: 10.1038/sj.cdd. 4401276

Schirmer, E. C., Glover, J. R., Singer, M. A., and Lindquist, S. (1996). HSP100/Clp proteins: a common mechanism explains diverse functions. Trends Biochem. Sci. 21, 289-296. doi: 10.1016/S0968-0004(96)10038-4

Schoettle, R. J., Kochanek, P. M., Magargee, M. J., Uhl, M. W., and Nemoto, E. M. (1990). Early polymorphonuclear leukocyte accumulation correlates with the development of posttraumatic cerebral edema in rats. J. Neurotrauma 7, 207217. doi: 10.1089/neu.1990.7.207

Schopf, F. H., Biebl, M. M., and Buchner, J. (2017). The HSP90 chaperone machinery. Nat. Rev. Mol. Cell Biol. 18, 345-360. doi: 10.1038/nrm.2017.20

Schwab, M. E. (2004). Nogo and axon regeneration. Curr. Opin. Neurobiol. 14, 118-124. doi: 10.1016/j.conb.2004.01.004

Sharp, F. R., Lu, A., Tang, Y., and Millhorn, D. E. (2000). Multiple molecular penumbras after focal cerebral ischemia. J. Cereb. Blood Flow Metab. 20, 10111032. doi: 10.1097/00004647-200007000-00001

Sharp, F. R., Zhan, X., and Liu, D.-Z. (2013). Heat shock proteins in the brain: role of Hsp70, Hsp 27, and HO-1 (Hsp32) and their therapeutic potential. Transl. Stroke Res. 4, 685-692. doi: 10.1007/s12975-013-0271-4

Sheedy, F. J., Grebe, A., Rayner, K. J., Kalantari, P., Ramkhelawon, B., Carpenter, S. B., et al. (2013). CD36 coordinates NLRP3 inflammasome activation by facilitating intracellular nucleation of soluble ligands into particulate ligands in sterile inflammation. Nat. Immunol. 14, 812-820. doi: 10.1038/ni.2639

Sheppard, P. W., Sun, X., Khammash, M., and Giffard, R. G. (2014). Overexpression of heat shock protein 72 attenuates NF- $\mathrm{kB}$ activation using a combination of regulatory mechanisms in microglia. PLoS Comput. Biol. 10, e1003471. doi: 10.1371/journal.pcbi.1003471

Shevtsov, M. A., Pozdnyakov, A. V., Mikhrina, A. L., Yakovleva, L. Y., Nikolaev, B. P., Dobrodumov, A. V., et al. (2014). Effective immunotherapy of rat glioblastoma with prolonged intratumoral delivery of exogenous heat shock protein Hsp70. Int. J. Cancer 135, 2118-2128. doi: 10.1002/ijc.28858

Shi, Y., Jiang, X., Zhang, L., Pu, H., Hu, X., Zhang, W., et al. (2017). Endotheliumtargeted overexpression of heat shock protein 27 ameliorates blood-brain barrier disruption after ischemic brain injury. Proc. Natl. Acad. Sci. U. S. A. 114, E1243-E1252. doi: 10.1073/pnas.1621174114
Shimada, Y., Shimura, H., Tanaka, R., Yamashiro, K., Koike, M., Uchiyama, Y., et al. (2018). Phosphorylated recombinant HSP27 protects the brain and attenuates blood-brain barrier disruption following stroke in mice receiving intravenous tissue-plasminogen activator. PLoS One 13, e0198039. doi: 10.1371/journal. pone.0198039

Shimura, H., Miura-Shimura, Y., and Kosik, K. S. (2004). Binding of tau to heat shock protein 27 leads to decreased concentration of hyperphosphorylated tau and enhanced cell survival. J. Biol. Chem. 279, 17957-17962. doi: 10.1074/jbc. M400351200

Simard, A. R., Soulet, D., Gowing, G., Julien, J.-P., and Rivest, S. (2006). Bone marrow-derived microglia play a critical role in restricting senile plaque formation in Alzheimer's disease. Neuron 49, 489-502. doi: 10.1016/j. neuron.2006.01.022

Singh, I. S., He, J.-R., Calderwood, S., and Hasday, J. D. (2002). A high affinity HSF- 1 binding site in the $5^{\prime}$-untranslated region of the murine tumor necrosis factor- $\alpha$ gene is a transcriptional repressor. J. Biol. Chem. 277, 4981-4988. doi: 10.1074/jbc.M108154200

Singh, M. K., Sharma, B., and Tiwari, P. K. (2017). The small heat shock protein Hsp27: present understanding and future prospects. J. Therm. Biol. 69, 149154. doi: 10.1016/j.jtherbio.2017.06.004

Soares, H. D., Hicks, R. R., Smith, D., and McIntosh, T. K. (1995). Inflammatory leukocytic recruitment and diffuse neuronal degeneration are separate pathological processes resulting from traumatic brain injury. J. Neurosci. 15, 8223-8233. doi: 10.1523/JNEUROSCI.15-12-08223.1995

Sochocka, M., Diniz, B. S., and Leszek, J. (2017). Inflammatory response in the CNS: friend or foe? Mol. Neurobiol. 54, 8071-8089. doi: 10.1007/s12035-016-0297-1

Söti, C., and Csermely, P. (2000). Molecular chaperones and the aging process. Biogerontology 1, 225-233. doi: 10.1023/A:1010082129022

Sozen, T., Tsuchiyama, R., Hasegawa, Y., Suzuki, H., Jadhav, V., Nishizawa, S., et al. (2009). Role of interleukin-1 $\beta$ in early brain injury after subarachnoid hemorrhage in mice. Stroke 40, 2519-2525. doi: 10.1161/ STROKEAHA.109.549592

Spera, P. A., Ellison, J. A., Feuerstein, G. Z., and Barone, F. C. (1998). IL-10 reduces rat brain injury following focal stroke. Neurosci. Lett. 251, 189-192. doi: 10.1016/S0304-3940(98)00537-0

Sreekumar, P. G., Kannan, R., Kitamura, M., Spee, C., Barron, E., Ryan, S. J., et al. (2010). $\alpha \mathrm{B}$ crystallin is apically secreted within exosomes by polarized human retinal pigment epithelium and provides neuroprotection to adjacent cells. PLoS One 5, e12578. doi: 10.1371/journal.pone.0012578

Stefano, L., Racchetti, G., Bianco, F., Passini, N., Gupta, R. S., Bordignon, P. P., et al. (2009). The surface-exposed chaperone, Hsp60, is an agonist of the microglial TREM2 receptor. J. Neurochem. 110, 284-294. doi: 10.1111/j.1471-4159.2009.06130.x

Stewart, C. R., Stuart, L. M., Wilkinson, K., van Gils, J. M., Deng, J., Halle, A., et al. (2010). CD36 ligands promote sterile inflammation through assembly of a toll-like receptor 4 and 6 heterodimer. Nat. Immunol. 11, 155-161. doi: 10.1038/ni.1836

Stope, M. B., Klinkmann, G., Diesing, K., Koensgen, D., Burchardt, M., and Mustea, A. (2017). Heat shock protein HSP27 Secretion by ovarian cancer cells is linked to intracellular expression levels, occurs independently of the endoplasmic reticulum pathway and hsp27's phosphorylation status, and is mediated by exosome liberation. Dis. Markers 2017, 1-12. doi: $10.1155 / 2017 / 1575374$

Su, X., Maguire-Zeiss, K. A., Giuliano, R., Prifti, L., Venkatesh, K., and Federoff, H. J. (2008). Synuclein activates microglia in a model of Parkinson's disease. Neurobiol. Aging 29, 1690-1701. doi: 10.1016/j.neurobiolaging.2007.04.006

Sulzer, D., Alcalay, R. N., Garretti, F., Cote, L., Kanter, E., Agin-Liebes, J., et al. (2017). T cells from patients with Parkinson's disease recognize a-synuclein peptides. Nature 546, 656-661. doi: 10.1038/nature22815

Sun, Y., Zhang, J., and Chen, S. (2017). Suppression of Alzheimer's disease-related phenotypes by the heat shock protein 70 inducer, geranylgeranylacetone, in APP/PS1 transgenic mice via the ERK/p38 MAPK signaling pathway. Exp. Ther. Med. 14, 5267-5274. doi: 10.3892/etm.2017.5253

Suzuki, S., and Kulkarni, A. B. (2010). Extracellular heat shock protein HSP90ß secreted by MG63 osteosarcoma cells inhibits activation of latent TGF- $\beta 1$. Biochem. Biophys. Res. Commun. 398, 525-531. doi: 10.1016/j.bbrc.2010.06.112

Swaroop, S., Mahadevan, A., Shankar, S. K., Adlakha, Y. K., and Basu, A. (2018). HSP60 critically regulates endogenous IL- $1 \beta$ production in activated microglia 
by stimulating NLRP3 inflammasome pathway. J. Neuroinflammation 15, 177. doi: 10.1186/s12974-018-1214-5

Swaroop, S., Sengupta, N., Suryawanshi, A. R., Adlakha, Y. K., and Basu, A. (2016). HSP60 plays a regulatory role in IL- $1 \beta$ - induced microglial inflammation via TLR4- p38 MAPK axis. J. Neuroinflammation 13, 27. doi: 10.1186/ s12974-016-0486-X

Sweeney, M. D., Zhao, Z., Montagne, A., Nelson, A. R., and Zlokovic, B. V. (2019). Blood-brain barrier: from physiology to disease and back. Physiol. Rev. 99, 21-78. doi: 10.1152/physrev.00050.2017

Szalay, G., Martinecz, B., Lénárt, N., Környei, Z., Orsolits, B., Judák, L., et al. (2016). Microglia protect against brain injury and their selective elimination dysregulates neuronal network activity after stroke. Nat. Commun. 7, 11499. doi: $10.1038 /$ ncomms 11499

Szczepanik, A. M., Funes, S., Petko, W., and Ringheim, G. E. (2001). IL-4, IL-10 and IL-13 modulate A beta(1-42)-induced cytokine and chemokine production in primary murine microglia and a human monocyte cell line. J. Neuroimmunol. 113, 49-62. doi: 10.1016/S0165-5728(00)00404-5

Takata, K., Kitamura, Y., Tsuchiya, D., Kawasaki, T., Taniguchi, T., and Shimohama, S. (2003). Heat shock protein-90-induced microglial clearance of exogenous amyloid-beta1-42 in rat hippocampus in vivo. Neurosci. Lett. 344, 87-90. doi: 10.1016/S0304-3940(03)00447-6

Takeuchi, T., Suzuki, M., Fujikake, N., Popiel, H. A., Kikuchi, H., Futaki, S., et al. (2015). Intercellular chaperone transmission via exosomes contributes to maintenance of protein homeostasis at the organismal level. Proc. Natl. Acad. Sci. 112, E2497-E2506. doi: 10.1073/pnas.1412651112

Takii, R., Inouye, S., Fujimoto, M., Nakamura, T., Shinkawa, T., Prakasam, R., et al. (2010). Heat shock transcription factor 1 inhibits expression of IL-6 through activating transcription factor 3. J. Immunol. 184, 1041-1048. doi: 10.4049/ jimmunol.0902579

Tang, D. D. (2015). Critical role of actin-associated proteins in smooth muscle contraction, cell proliferation, airway hyperresponsiveness and airway remodeling. Respir. Res. 16, 134. doi: 10.1186/s12931-015-0296-1

Tarkowski, E., Andreasen, N., Tarkowski, A., and Blennow, K. (2003). Intrathecal inflammation precedes development of Alzheimer's disease. J. Neurol. Neurosurg. Psychiatry 74, 1200-1205. doi: 10.1136/jnnp.74.9.1200

Taylor, A. R., Robinson, M. B., Gifondorwa, D. J., Tytell, M., and Milligan, C. E. (2007). Regulation of heat shock protein 70 release in astrocytes: role of signaling kinases. Dev. Neurobiol. 67, 1815-1829. doi: 10.1002/dneu.20559

Thériault, J. R., Adachi, H., and Calderwood, S. K. (2006). Role of scavenger receptors in the binding and internalization of heat shock protein $70 . \mathrm{J}$. Immunol. 177, 8604-8611. doi: 10.4049/jimmunol.177.12.8604

Thirstrup, K., Sotty, F., Montezinho, L. C. P., Badolo, L., Thougaard, A., Kristjánsson, M., et al. (2016). Linking HSP90 target occupancy to HSP70 induction and efficacy in mouse brain. Pharmacol. Res. 104, 197-205. doi: 10.1016/j.phrs.2015.12.028

Thuringer, D., Berthenet, K., Cronier, L., Solary, E., and Garrido, C. (2015). Primary tumor- and metastasis-derived colon cancer cells differently modulate connexin expression and function in human capillary endothelial cells. Oncotarget 6, 28800-28815. doi: 10.18632/oncotarget.4894

Tidwell, J. L., Houenou, L. J., and Tytell, M. (2004). Administration of Hsp70 in vivo inhibits motor and sensory neuron degeneration. Cell Stress Chaperones 9 , 88-98. doi: 10.1379/CSC-9R.1

Tokuda, H., Kuroyanagi, G., Onuma, T., Enomoto, Y., Doi, T., Iida, H., et al. (2018). Ristocetin induces phosphorylated-HSP27 (HSPB1) release from the platelets of type 2 DM patients: anti-platelet agent-effect on the release. Biomed. Rep. 8 , 365-372. doi: 10.3892/br.2018.1058

Török, Z., Crul, T., Maresca, B., Schütz, G., Viana F., Dindia, L., et al. (2014). Plasma membranes as heat stress sensors: from lipid-controlled molecular switches to therapeutic applications. Biochim. Biophys. Acta 1838, 1594-1618. doi: 10.1016/j.bbamem.2013.12.015

Tóth, M. E., Gonda, S., Vigh, L., and Santha, M. (2010). Neuroprotective effect of small heat shock protein, Hsp27, after acute and chronic alcohol administration. Cell Stress Chaperones 15, 807-817. doi: 10.1007/s12192-010-0188-8

Tóth, M. E., Szegedi, V., Varga, E., Juhász, G., Horváth, J., Borbély, E., et al. (2013). Overexpression of Hsp27 ameliorates symptoms of Alzheimer's disease in APP/ PS1 mice. Cell Stress Chaperones 18, 759-771. doi: 10.1007/s12192-013-0428-9

Tóth, M. E., Gombos, I., and Sántha, M. (2015). Heat shock proteins and their role in human diseases. Acta Biol. Szeged. 59, 121-141.
Tytell, M., Greenberg, S. G., and Lasek, R. J. (1986). Heat shock-like protein is transferred from glia to axon. Brain Res. 363, 161-164. doi: 10.1016/0006-8993(86)90671-2

Uchida, S., Fujiki, M., Nagai, Y., Abe, T., and Kobayashi, H. (2006). Geranylgeranylacetone, a noninvasive heat shock protein inducer, induces protein kinase $\mathrm{C}$ and leads to neuroprotection against cerebral infarction in rats. Neurosci. Lett. 396, 220-224. doi: 10.1016/j.neulet.2005.11.065

van der Weerd, L., Tariq Akbar, M., Aron Badin, R., Valentim, L. M., Thomas, D. L., Wells, D. J., et al. (2010). Overexpression of heat shock protein 27 reduces cortical damage after cerebral ischemia. J. Cereb. Blood Flow Metab. 30, 849856. doi: $10.1038 / \mathrm{jcbfm} .2009 .249$

van Eden, W., Spiering, R., Broere, F., and van der Zee, R. (2012). A case of mistaken identity: HSPs are no DAMPs but DAMPERs. Cell Stress Chaperones 17, 281-292. doi: 10.1007/s12192-011-0311-5

van Eden, W., van der Zee, R., and Prakken, B. (2005). Heat-shock proteins induce T-cell regulation of chronic inflammation. Nat. Rev. Immunol. 5, 318-330. doi: $10.1038 /$ nri1593

Van Montfort, R., Slingsby, C., and Vierling, E. (2001). Structure and function of the small heat shock protein/alpha-crystallin family of molecular chaperones. Adv. Protein Chem. 59, 105-156. doi: 10.1016/S0065-3233(01)59004-X

van Noort, J. M. (2008). Stress proteins in CNS inflammation. J. Pathol. 214 (2), 267-275. doi: 10.1002/path.2273

van Noort, J. M., Bsibsi, M., Nacken, P., Gerritsen, W. H., and Amor, S. (2012). The link between small heat shock proteins and the immune system. Int. J. Biochem. Cell Biol. 44, 1670-1679. doi: 10.1016/j.biocel.2011.12.010

VanPelt, J., and Page, R. C. (2017). Unraveling the CHIP : Hsp70 complex as an information processor for protein quality control. Biochim. Biophys. Acta Proteins Proteomics 1865, 133-141. doi: 10.1016/j.bbapap.2016.11.005

Vega, V. L., Rodriguez-Silva, M., Frey, T., Gehrmann, M., Diaz, J. C., Steinem, C., et al. (2008). Hsp70 translocates into the plasma membrane after stress and is released into the extracellular environment in a membrane-associated form that activates macrophages. J. Immunol. 180, 4299-4307. doi: 10.4049/ jimmunol.180.6.4299

Vieira, D. B., and Gamarra, L. F. (2016). Getting into the brain: liposome-based strategies for effective drug delivery across the blood-brain barrier. Int. J. Nanomedicine 11, 5381-5414. doi: 10.2147/IJN.S117210

Vígh, L., Literáti, P. N., Horváth, I., Török, Z., Balogh, G., Glatz, A., et al. (1997). Bimoclomol: a nontoxic, hydroxylamine derivative with stress proteininducing activity and cytoprotective effects. Nat. Med. 3, 1150-1154. doi: 10.1038/nm1097-1150

Vigh, L., Nakamoto, H., Landry, J., Gomez-Munoz, A., Harwood, J. L., and Horvath, I. (2007). Membrane regulation of the stress response from prokaryotic models to mammalian cells. Ann. N. Y. Acad. Sci. 1113, 40-51. doi: 10.1196/annals.1391.027

Vogel, D. Y. S., Glim, J. E., Stavenuiter, A. W. D., Breur, M., Heijnen, P., Amor, S., et al. (2014). Human macrophage polarization in vitro: maturation and activation methods compared. Immunobiology 219, 695-703. doi: 10.1016/j. imbio.2014.05.002

Walker, D. G., Kim, S. U., and McGeer, P. L. (1995). Complement and cytokine gene expression in cultured microglial derived from postmortem human brains. J. Neurosci. Res. 40, 478-493. doi: 10.1002/jnr.490400407

Wang, B., Liu, Y., Huang, L., Chen, J., Li, J. J., Wang, R., et al. (2017). A CNSpermeable Hsp90 inhibitor rescues synaptic dysfunction and memory loss in APP-overexpressing Alzheimer's mouse model via an HSF1-mediated mechanism. Mol. Psychiatry 22, 990-1001. doi: 10.1038/mp.2016.104

Wang, H., Wang, X., Xie, C., Zhang, M., Ruan, H., Wang, S., et al. (2018b). Nanodisk-based glioma-targeted drug delivery enabled by a stable glycopeptide. J. Control. Release 284, 26-38. doi: 10.1016/j.jconrel.2018.06.006

Wang, R., Kovalchin, J. T., Muhlenkamp, P., and Chandawarkar, R. Y. (2006). Exogenous heat shock protein 70 binds macrophage lipid raft microdomain and stimulates phagocytosis, processing, and MHC-II presentation of antigens. Blood 107, 1636-1642. doi: 10.1182/blood-2005-06-2559

Wang, W., Zinsmaier, A. K., Firestone, E., Lin, R., Yatskievych, T. A., Yang, S., et al. (2018a). Blocking tumor necrosis factor-alpha expression prevents blastinduced excitatory/inhibitory synaptic imbalance and parvalbumin-positive interneuron loss in the hippocampus. J. Neurotrauma 35, 2306-2316. doi: $10.1089 /$ neu.2018.5688 
Wattananit, S., Tornero, D., Graubardt, N., Memanishvili, T., Monni, E., Tatarishvili, J., et al. (2016). Monocyte-derived macrophages contribute to spontaneous long-term functional recovery after stroke in mice. J. Neurosci. 36, 4182-4195. doi: 10.1523/JNEUROSCI.4317-15.2016

Waudby, C. A., Knowles, T. P. J., Devlin, G. L., Skepper, J. N., Ecroyd, H., Carver, J. A., et al. (2010). The interaction of aB-crystallin with mature $\alpha$-synuclein amyloid fibrils inhibits their elongation. Biophys. J. 98, 843-851. doi: 10.1016/j.bpj.2009.10.056

Westerheide, S. D., Bosman, J. D., Mbadugha, B. N. A., Kawahara, T. L. A., Matsumoto, G., Kim, S., et al. (2004). Celastrols as inducers of the heat shock response and cytoprotection. J. Biol. Chem. 279, 56053-56060. doi: 10.1074/ jbc.M409267200

Wilhelmus, M.M.M., Otte-Holler,I., Wesseling, P., de Waal, R.M.W., Boelens, W.C., and Verbeek, M. M. (2006a). Specific association of small heat shock proteins with the pathological hallmarks of Alzheimer's disease brains. Neuropathol. Appl. Neurobiol. 32, 119-130. doi: 10.1111/j.1365-2990.2006.00689.x

Wilhelmus, M. M., Boelens, W. C., Otte-Höller, I., Kamps, B., de Waal, R. M., and Verbeek, M. M. (2006b). Small heat shock proteins inhibit amyloid-beta protein aggregation and cerebrovascular amyloid-beta proteintoxicity. Brain Res. 1089, 67-78. doi: 10.1016/j.brainres.2006.03.058

Wong, R., Lénárt, N., Hill, L., Toms, L., Coutts, G., Martinecz, B., et al. (2019). Interleukin-1 mediates ischaemic brain injury via distinct actions on endothelial cells and cholinergic neurons. Brain Behav. Immun. 76, 126-138. doi: 10.1016/j.bbi.2018.11.012

Wu, N., Wang, Y.-H., Zhao, H.-S., Liu, D.-N., Ying, X., Yin, Z.-Q., et al. (2009). Alpha-crystallin downregulates the expression of TNF-alpha and iNOS by activated rat retinal microglia in vitro and in vivo. Ophthalmic Res. 42, 21-28. doi: 10.1159/000219681

Wyttenbach, A., Sauvageot, O., Carmichael, J., Diaz-Latoud, C., Arrigo, A.-P., and Rubinsztein, D. C. (2002). Heat shock protein 27 prevents cellular polyglutamine toxicity and suppresses the increase of reactive oxygen species caused by huntingtin. Hum. Mol. Genet. 11, 1137-1151. doi: 10.1093/hmg/11.9.1137

Xiao, X., Zuo, X., Davis, A. A., McMillan, D. R., Curry, B. B., Richardson, J. A., et al. (1999). HSF1 is required for extra-embryonic development, postnatal growth and protection during inflammatory responses in mice. EMBO J. 18, 5943-5952. doi: 10.1093/emboj/18.21.5943

Xie, J., Zhu, H., Guo, L., Ruan, Y., Wang, L., Sun, L., et al. (2010a). Lectin-like oxidized low-density lipoprotein receptor-1 delivers heat shock protein 60 -fused antigen into the MHC class I presentation pathway. J. Immunol. 185, 2306-2313. doi: 10.4049/jimmunol.0903214

Xie, Y., Bai, O., Zhang, H., Yuan, J., Zong, S., Chibbar, R., et al. (2010b). Membranebound HSP70-engineered myeloma cell-derived exosomes stimulate more efficient CD8+ CTL- and NK-mediated antitumour immunity than exosomes released from heat-shocked tumour cells expressing cytoplasmic HSP70. J. Cell. Mol. Med. 14, 2655-2666. doi: 10.1111/j.1582-4934.2009.00851.x

Xu, K., Sun, X., Erokwu, B. O., Cernak, I., and LaManna, J. C. (2011). A heatshock protein co-inducer treatment improves behavioral performance in rats exposed to hypoxia. Adv. Exp. Med. Biol. 701, 313-318. doi: 10.1007/978-1-4419-7756-4_42

Xu, Z., Shi, W.-H., Xu, L.-B., Shao, M.-F., Chen, Z.-P., Zhu, G.-C., et al. (2019). Resident microglia activate before peripheral monocyte infiltration and p75NTR blockade reduces microglial activation and early brain injury after subarachnoid hemorrhage. ACS Chem. Neurosci. 10, 412-423. doi: 10.1021/ acschemneuro.8b00298
Yan, D., Saito, K., Ohmi, Y., Fujie, N., and Ohtsuka, K. (2004). Paeoniflorin, a novel heat shock protein-inducing compound. Cell Stress Chaperones 9, 378-389. doi: 10.1379/CSC-51R.1

Yang, H.-M., Yang, S., Huang, S.-S., Tang, B.-S., and Guo, J.-F. (2017). Microglial activation in the pathogenesis of Huntington's disease. Front. Aging Neurosci. 9, 193. doi: 10.3389/fnagi.2017.00193

Yenari, M. A., Xu, L., Tang, X. N., Qiao, Y., and Giffard, R. G. (2006). Microglia potentiate damage to blood-brain barrier constituents: improvement by minocycline in vivo and in vitro. Stroke 37, 1087-1093. doi: 10.1161/01. STR.0000206281.77178.ac

Yurinskaya, M. M., Mit'kevich, V. A., Barykin, E. P., Garbuz, D. G., Evgen'ev, M. B., Makarov, A. A., et al. (2015). Heat-shock protein Hsp70 protects neuroblastoma cells SK-N-SH from the neurotoxic effects of hydrogen peroxide and the betaamyloid peptide. Mol. Biol. 49, 924-927. doi: 10.1134/S0026893315060230

Zhang, D., Sun, L., Zhu, H., Wang, L., Wu, W., Xie, J., et al. (2012). Microglial LOX-1 reacts with extracellular HSP60 to bridge neuroinflammation and neurotoxicity. Neurochem. Int. 61, 1021-1035. doi: 10.1016/j.neuint.2012.07.019

Zhang, Y., Li, H., Huang, M., Huang, M., Chu, K., Xu, W., et al. (2015). Paeoniflorin, a monoterpene glycoside, protects the brain from cerebral ischemic injury via inhibition of apoptosis. Am. J. Chin. Med. 43, 543-557. doi: 10.1142/ S0192415X15500342

Zhang, Z., Chopp, M., and Powers, C. (1997). Temporal profile of microglial response following transient $(2 \mathrm{~h})$ middle cerebral artery occlusion. Brain Res. 744, 189-198. doi: 10.1016/S0006-8993(96)01085-2

Zhao, Z., Faden, A. I., Loane, D. J., Lipinski, M. M., Sabirzhanov, B., and Stoica, B. A. (2013). Neuroprotective effects of geranylgeranylacetone in experimental traumatic brain injury. J. Cereb. Blood Flow Metab. 33, 1897-1908. doi: 10.1038/ jcbfm.2013.144

Zheng, Z., Kim, J. Y., Ma, H., Lee, J. E., and Yenari, M. A. (2008). Anti-inflammatory effects of the $70 \mathrm{kDa}$ heat shock protein in experimental stroke. J. Cereb. Blood Flow Metab. 28, 53-63. doi: 10.1038/sj.jcbfm.9600502

Zhu, Z., and Reiser, G. (2018). The small heat shock proteins, especially HspB4 and HspB5 are promising protectants in neurodegenerative diseases. Neurochem. Int. 115, 69-79. doi: 10.1016/j.neuint.2018.02.006

Zininga, T., Ramatsui, L., and Shonhai, A. (2018). Heat shock proteins as immunomodulants. Molecules 23, 2846, 1-17. doi: 10.3390/molecules23112846

Zourlidou, A., Payne Smith, M. D., and Latchman, D. S. (2004). HSP27 but not HSP70 has a potent protective effect against alpha-synuclein-induced cell death in mammalian neuronal cells. J. Neurochem. 88, 1439-1448. doi: 10.1046/j.1471-4159.2003.02273.x

Zuehlke, A. D., Moses, M. A., and Neckers, L. (2018). Heat shock protein 90: its inhibition and function. Philos. Trans. R. Soc. B Biol. Sci. 373, 20160527. doi: $10.1098 /$ rstb.2016.0527

Conflict of Interest Statement: The authors declare that the research was conducted in the absence of any commercial or financial relationships that could be construed as a potential conflict of interest.

Copyright (c) 2019 Dukay, Csoboz and Tóth. This is an open-access article distributed under the terms of the Creative Commons Attribution License (CC BY). The use, distribution or reproduction in other forums is permitted, provided the original author(s) and the copyright owner(s) are credited and that the original publication in this journal is cited, in accordance with accepted academic practice. No use distribution or reproduction is permitted which does not comply with these terms. 